\title{
Pre- and post-perihelion observations of C/2009 P1 (Garradd): Evidence for an oxygen-rich heritage?
}

\author{
Michael A. DiSanti ${ }^{\mathrm{a}, \mathrm{b}, *}$, Geronimo L. Villanueva ${ }^{\mathrm{a}, \mathrm{c}}$, Lucas Paganini ${ }^{\mathrm{a}, \mathrm{c}, \mathrm{d}}$, Boncho P. Bonev ${ }^{\mathrm{a}, \mathrm{c}}$, \\ Jacqueline V. Keane ${ }^{\mathrm{e}, \mathrm{f}}$, Karen J. Meech ${ }^{\mathrm{e}, \mathrm{f}}$, Michael J. Mumma ${ }^{\mathrm{a}, \mathrm{b}}$ \\ ${ }^{a}$ Goddard Center for Astrobiology, NASA Goddard Space Flight Center, Greenbelt, MD 20771, USA \\ ${ }^{\mathrm{b}}$ Solar System Exploration Division, Mail Stop 690, NASA Goddard Space Flight Center, Greenbelt, MD 20771, USA \\ ${ }^{\mathrm{C}}$ Department of Physics, Catholic University of America, Washington, DC 20064, USA \\ ${ }^{\mathrm{d}}$ NASA Postdoctoral Program, Oak Ridge Associated Universities, Oak Ridge, TN 37830, USA \\ ${ }^{\mathrm{e}}$ University of Hawaii NASA Astrobiology Institute, Honolulu, HI 96722, USA \\ f Institute for Astronomy, University of Hawaii, 2680 Woodlawn Drive, Honolulu, HI 96822, USA
}

\section{A R T I C L E I N F O}

\section{Article history:}

Received 22 April 2013

Revised 4 September 2013

Accepted 4 September 2013

Available online 19 September 2013

\section{Keywords:}

Comets, composition

Spectroscopy

Comets, coma

Comets, origin

\begin{abstract}
A B S T R A C T
We conducted pre- and post-perihelion observations of Comet C/2009 P1 (Garradd) on UT 2011 October 13 and 2012 January 8, at heliocentric distances of 1.83 and $1.57 \mathrm{AU}$, respectively, using the high-resolution infrared spectrometer (NIRSPEC) at the Keck II 10-m telescope on Mauna Kea, HI. Pre-perihelion, we obtained production rates for nine primary volatiles (native ices): $\mathrm{H}_{2} \mathrm{O}, \mathrm{CO}, \mathrm{CH}_{3} \mathrm{OH}, \mathrm{CH}_{4}, \mathrm{C}_{2} \mathrm{H}_{6}, \mathrm{HCN}, \mathrm{C}_{2} \mathrm{H}_{2}$, $\mathrm{H}_{2} \mathrm{CO}$, and $\mathrm{NH}_{3}$. Post-perihelion, we obtained production rates for three of these $\left(\mathrm{H}_{2} \mathrm{O}, \mathrm{CH}_{4}\right.$, and $\left.\mathrm{HCN}\right)$ and sensitive upper limits for three others $\left(\mathrm{C}_{2} \mathrm{H}_{2}, \mathrm{H}_{2} \mathrm{CO}\right.$, and $\left.\mathrm{NH}_{3}\right)$. $\mathrm{CO}$ was enriched and $\mathrm{C}_{2} \mathrm{H}_{2}$ was depleted, yet $\mathrm{C}_{2} \mathrm{H}_{6}$ and $\mathrm{CH}_{3} \mathrm{OH}$ were close to their current mean values as measured in a dominant group of Oort cloud comets. This may indicate processing of its pre-cometary ices in a relatively oxygen-rich environment.

Our measurements indicate consistent pre- and post-perihelion abundance ratios relative to $\mathrm{H}_{2} \mathrm{O}$, suggesting we were measuring compositional homogeneity among measured species to the depths in the nucleus sampled. However, the overall gas production was lower post-perihelion despite its smaller heliocentric distance on January 8 . This is qualitatively consistent with other studies of C/2009 P1, perhaps due to seasonal differences in the heating of one or more active regions on the nucleus.

On October 13, the water profile showed a pronounced excess towards the Sun-facing hemisphere that was not seen in other molecules, including $\mathrm{H}_{2} \mathrm{O}$ on January 8 , nor in the dust continuum. Inter-comparison of profiles from October 13 permitted us to quantify contributions due to release of $\mathrm{H}_{2} \mathrm{O}$ from the nucleus, and from its release in the coma. This resulted in the latter source contributing $25-30 \%$ of the total observed water within our slit, which covered roughly $\pm 300 \mathrm{~km}$ by $\pm 4500 \mathrm{~km}$ from the nucleus. We attribute this excess $\mathrm{H}_{2} \mathrm{O}$, which peaked at a mean projected distance of $1300-1500 \mathrm{~km}$ from the nucleus, to release from water-rich, relatively pure icy grains.
\end{abstract}

Published by Elsevier Inc.

\section{Introduction}

More than any other Solar System material, the ices contained in the nuclei of comets (i.e., their native ices) ${ }^{1}$ retain a relatively well-preserved record of conditions when and where these primitive small bodies formed. Comets reside for long periods of time in the outer Solar System, and clues to its formation and evolution are provided through their volatile compositions (e.g., see reviews by Mum-

\footnotetext{
* Corresponding author at: Goddard Center for Astrobiology, NASA Goddard Space Flight Center, Mail Stop 693.0, Greenbelt, MD 20771, USA.

E-mail address: michael.a.disanti@nasa.gov (M.A. DiSanti).

1 We use the term "native ices" to refer to those housed in the nucleus, which upon sublimation release primary volatiles into the coma.
}

ma and Charnley, 2011; DiSanti and Mumma, 2008; BockeléeMorvan et al., 2005).

Comets today belong to (at least) two distinct dynamical reservoirs, the Kuiper Belt (KB) and the Oort cloud (OC), thought to be the dominant source regions for ecliptic and nearly isotropic (long-period and dynamically-new) comets, respectively. Until relatively recently it was thought that short-period comets formed more or less in situ in the KB (at heliocentric distances $R_{h}>30 \mathrm{AU}$ ), while those from the OC formed in the $R_{h} \sim 5-30 \mathrm{AU}$ region and were subsequently ejected through gravitational interaction with the giant planets. If true, this suggested distinctly differing compositions might be expected for these two dynamical populations of comets (Mumma et al., 1993).

This reasoning has since evolved to new paradigms, stemming from the Nice model (Gomes et al., 2005; Morbidelli et al., 2008) 
Table 1

Observing Log for C/2009 P1 (Garradd). ${ }^{a}$

\begin{tabular}{|c|c|c|c|}
\hline NIRSPEC setting & UT start-end & Molecule (order) ${ }^{\mathrm{b}}$ & $T_{\text {int }}{ }^{\mathrm{c}}(\mathrm{min})$ \\
\hline \multicolumn{4}{|c|}{$\begin{array}{l}\text { Pre-perihelion - UT } 2011 \text { October } 13 \\
R_{h}=1.830 \mathrm{AU}, \Delta=1.836 \mathrm{AU}, \mathrm{d} \Delta / \mathrm{d} t=+19.2 \mathrm{~km} \mathrm{~s}^{-1}, \mathrm{~d} R_{h} / \mathrm{d} t=-12.2 \mathrm{~km} \mathrm{~s}^{-1}\end{array}$} \\
\hline KL2 & $04: 42-05: 42$ & $\begin{array}{l}\mathrm{H}_{2} \mathrm{O}(26) \\
\mathrm{HCN}, \mathrm{C}_{2} \mathrm{H}_{2}, \mathrm{NH}_{3}(25) \\
\mathrm{CH}_{4}(23) \\
\mathrm{H}_{2} \mathrm{CO}(21)\end{array}$ & 36 \\
\hline MWA & $05: 52-06: 15$ & $\begin{array}{l}\mathrm{H}_{2} \mathrm{O}(15,16) \\
\mathrm{CO}(16)\end{array}$ & 8 \\
\hline KL1 & $06: 26-06: 35$ & $\begin{array}{l}\mathrm{H}_{2} \mathrm{O}(26,27) \\
\mathrm{C}_{2} \mathrm{H}_{6}(23) \\
\mathrm{CH}_{3} \mathrm{OH}(22,23)\end{array}$ & 6 \\
\hline \multicolumn{4}{|c|}{ Post-perihelion - UT 2012 January 8} \\
\hline KL2 & $15: 21: 15: 43$ & $\begin{array}{l}\mathrm{H}_{2} \mathrm{O}(26) \\
\mathrm{HCN}, \mathrm{C}_{2} \mathrm{H}_{2}, \mathrm{NH}_{3}(25) \\
\mathrm{CH}_{4}(23) \\
\mathrm{H}_{2} \mathrm{CO}(21)\end{array}$ & 15 \\
\hline
\end{tabular}

that predicts considerable disruption of the outer Solar System due to outward migration of young Saturn through the 1:2 orbital resonance with Jupiter. The more recent "Grand Tack" model (Walsh and Morbidelli, 2011) invokes inward migration of the giant planets within the first $5 \times 10^{6}$ years of the Solar System - as a means of explaining the relatively small mass of Mars and also the formation of small bodies (especially asteroids) in the inner Solar System ( $\left.R_{h} \sim 1-3 \mathrm{AU}\right)$ - followed by their outward migration. These models predict compositional "blurring" of comets along dynamical lines, in the sense that diversity in cometary compositions should exist in both $\mathrm{KB}$ and $\mathrm{OC}$ reservoirs, and indeed this is observed. The models however do not account for the observed discovery rate of nearly isotropic comets. As a result, it was argued that a large fraction (up to 90\%) of OC comets may have originated in the environs of neighboring stars in the Sun's birth cluster (Levison et al., 2010), although more recent modeling suggests revising this fraction downward (Brasser et al., 2012).

Here we report abundances for nine primary volatiles in the dynamically new Comet C/2009 P1 (Garradd; hereafter C/2009 P1) based on observations obtained near $R_{h}=1.8 \mathrm{AU}$ pre-perihelion and 1.6 AU post-perihelion. We compare our results with other infrared studies of C/2009 P1, place them in the context of our ongoing compositional taxonomy among comets measured to date, and discuss possible implications regarding the processing history of the ices in this comet. We compare spatial emission profiles, and thereby estimate the fraction of $\mathrm{H}_{2} \mathrm{O}$ released from what appear to be water-rich grains in the coma.

\section{Observations and data processing}

We observed C/2009 P1 pre-perihelion on UT 2011 October 13, and also shortly following perihelion (December 23, $q=1.55 \mathrm{AU}$ ) on 2012 January 8 (Table 1 ) using the NIRSPEC infrared high-resolution $(\lambda / \Delta \lambda \sim 24,000)$ spectrometer (McLean et al., 1998, 2000) at the Keck II 10-m telescope on Mauna Kea, Hawaii. On October 13, C/2009 P1 reached the Keck II west elevation limit at 06:32 UT, which translated to approximately $1 \mathrm{~h}$ and $40 \mathrm{~min}$ of clock time following focus and acquisition at the start of the night. In spite of this limited available time, the combination of broad spectral coverage and high-throughput optics afforded by NIRSPEC allowed us to sample a large suite of primary volatiles using three distinct cross-disperser/echelle combinations (Table 1). On January 8,
C/2009 P1 became available in the east toward the end of the night, only allowing accommodation of a setting that encompasses the largest number of organic molecules simultaneously with $\mathrm{H}_{2} \mathrm{O}$.

For our observations, we oriented the slit along the Sun-comet line $\left(\mathrm{PA}=76^{\circ} \text { on October } 13,330^{\circ} \text { on January } 8\right)^{2}$, which was maintained throughout our observations of C/2009 P1 by using NIRSPEC in active rotator (i.e., 'Position Angle') mode. Comet and supporting flux standard star spectral frames (Table 1, note 'a') were acquired in our standard ABBA cadence, with both A- and B-beams present in the slit (e.g., see Villanueva et al., 2011a; Bonev, 2005; DiSanti et al., 2006; Mumma et al., 2001a) and separated by 12 arcsec.

Cometary and stellar data were processed using our custom algorithms (e.g., Villanueva et al., 2011a; Bonev, 2005; DiSanti et al., 2001 ) that correct for anamorphic optics and provide highly accurate spatial and spectral registrations. We matched abundances of molecular absorbers in the terrestrial atmosphere to extracted spectra, using the Line-By-Line Radiative Transfer Model (LBLRTM; Clough et al., 2005) together with our custom updates (Villanueva et al., 2011b). The high terrestrial water burden on October 13 ( $\sim 5$ precipitable $\mathrm{mm}$ ) limited the number of accessible cometary water lines, particularly in order 27 of the KL1 setting (see Section 3.1). The water burden on January 8 was relatively modest $(\sim 1.5 \mathrm{~mm})$, however the air mass of C/2009 P1 was higher compared with October 13 . Spectral extracts, representing sums over nine spatial pixels ( 1.78 arcsec) centered on peak emission intensities, are shown for October 13 (Figs. 1 and 2) and January 8 (Fig. 3).

\section{Rotational temperatures, production rates, and spatial distributions}

\subsection{Excitation analysis}

Because vibrational bands are in general not sampled completely, obtaining accurate production rates for observed molecules requires knowledge of the relative populations of their rotational levels. These are characterized by a rotational temperature $\left(T_{\text {rot }}\right)$, determined by comparing observed and modeled intensities (fluorescence efficiencies; i.e., g-factors) for emission lines

\footnotetext{
2 Position Angle (PA) is defined as the direction in the sky plane of the extended heliocentric radius vector measured eastward from north, termed "PsAng" in the JPLHorizons system (http://ssd.jpl.nasa.gov/horizons.cgi).
} 

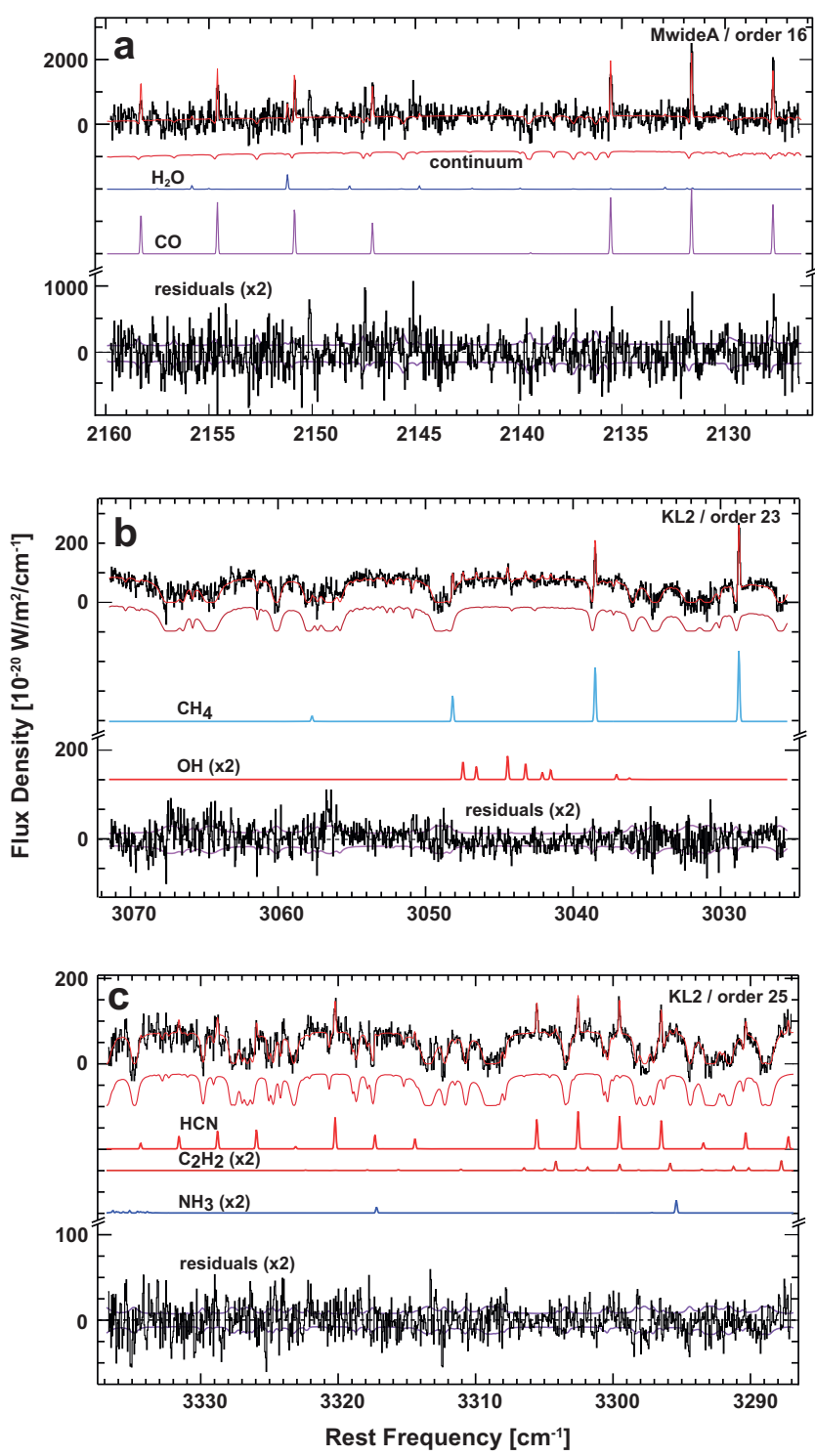

Fig. 1. Spectral extracts for several echelle orders, with modeled continuum and molecular emissions in C/2009 P1 on UT 2011 October 13. Residuals and $\pm 1 \sigma$ stochastic noise envelopes are also shown.

spanning a sufficiently large range of rotational energies. Our line g-factors are based on ro-vibrational band fluorescence models we developed for each molecule: $\mathrm{H}_{2} \mathrm{O}$ multiple bands (Figs. 1a, 2c and 3c; Villanueva et al., 2012a), $\mathrm{OH}^{*} v_{1}$ and $v_{2}-v_{1}$ (Figs. $1 \mathrm{~b}$, 2c and 3a-3c; Bonev, 2005, Bonev et al., 2006), $\mathrm{C}_{2} \mathrm{H}_{6} v_{7}$ (Fig. 2a; Villanueva et al., 2011b), $\mathrm{CH}_{4} v_{3}$ (Figs. 1b and 3b; Gibb et al., 2003), $\mathrm{C}_{2} \mathrm{H}_{2} v_{3}$ and $v_{2}+v_{4}+v_{5}$ (Figs. $1 \mathrm{c}$ and 3a), CO $v_{1}$ (Fig. 1a) (Villanueva et al., 2011a), $\mathrm{NH}_{3} v_{1}$ and $v_{3}$ (Figs. 1c and 3a; Villanueva et al., 2013; Kawakita and Mumma, 2011), HCN $v_{1}$ (Figs. 1c and 3a; Lippi et al., 2013; Villanueva et al., 2013), $\mathrm{H}_{2} \mathrm{CO} v_{1}$ and $v_{5}$ (Reuter et al., 1989; DiSanti et al., 2006), and $\mathrm{CH}_{3} \mathrm{OH} v_{2}$ (Fig. 2a; DiSanti et al., 2013) and $v_{3}$ (Fig. 2b; Villanueva et al., 2012b). These models make use of a realistic solar flux that includes Fraunhofer lines and incorporates the cometary heliocentric velocity $\left(\mathrm{d} R_{h} / \mathrm{d} t\right.$ in Table 1$)$ in calculating fluorescent pumping rates (see Villanueva et al., 2011a for additional details).

The high terrestrial water burden on October 13 resulted in poor transmittance for many of the cometary $\mathrm{H}_{2} \mathrm{O}$ lines, and so introduced correspondingly large uncertainties in line-by-line production rates retrieved from transmittance-corrected line fluxes
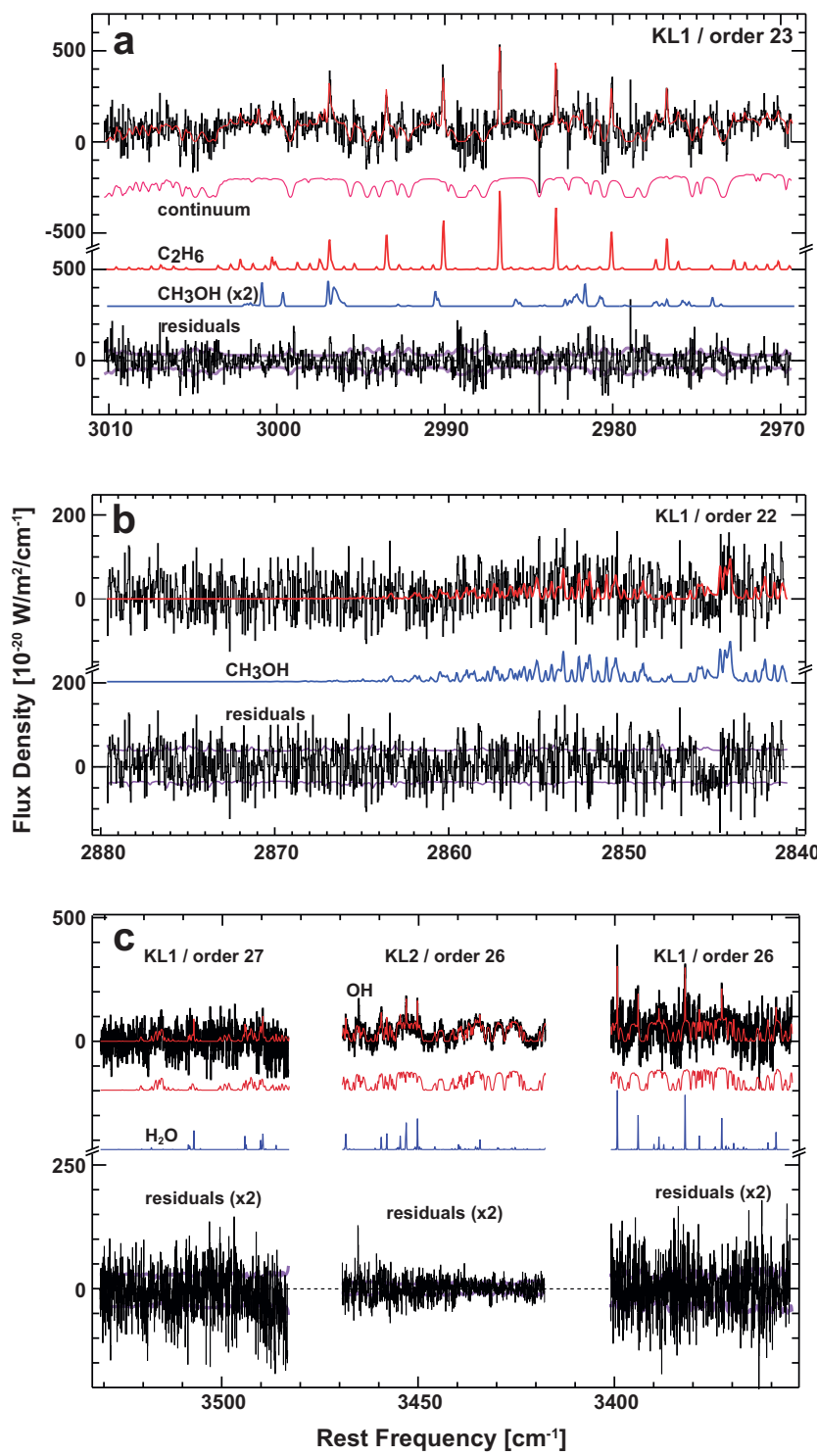

Fig. 2. Additional spectral extracts for C/2009 P1 on UT 2011 October 13. The $\mathrm{OH}$ line indicated in panel $\mathrm{c}$ here and in Fig. $3 \mathrm{c}$ is a combination of fluorescent and prompt emission.

(see Eq. (1) below). The $\mathrm{H}_{2} \mathrm{O}$ line near $3514.4 \mathrm{~cm}^{-1}$ (rest frequency) is normally the strongest observed in the L-band, but it suffered from high opacity (transmittance less than $1 \%$ ), and was not detected (Fig. 2c). Using observed lines in the three orders shown in Fig. 2c yielded a poorly constrained rotational temperature for water $\left(T_{\text {rot }}=42^{+26} /-24 \mathrm{~K}\right)$.

We retrieved more precise rotational temperatures independently for $\mathrm{HCN}, \mathrm{CH}_{4}, \mathrm{CO}, \mathrm{C}_{2} \mathrm{H}_{6}$, and $\mathrm{CH}_{3} \mathrm{OH}$ on October 13 (Table 2). Their weighted mean value ( $T_{\text {rot }}=48 \pm 4 \mathrm{~K} ; 1 \sigma$ uncertainty) is consistent with $T_{\text {rot }}$ measured for C/2009 P1 near $R_{h}=2.1$ AU (40 $\pm 7 \mathrm{~K}$; Villanueva et al., 2012c) and $2.0 \mathrm{AU}$ (50 K; Paganini et al., 2012). We take our weighted mean $T_{\text {rot }}(48 \mathrm{~K})$ to be the most probable temperature, and adopt this for all molecules on October 13. From our January 8 observations, we measured $T_{\text {rot }}=55 \pm 10 \mathrm{~K}$ based on water lines in order 26 (Fig. $3 \mathrm{c}$ ). We were unable to determine $T_{\text {rot }}$ for $\mathrm{HCN}$ nor $\mathrm{CH}_{4}$, and therefore adopt $55 \mathrm{~K}$ for all molecules measured on January 8.

We note that individual values of $T_{\text {rot }}$ measured on October 13 agree within their $1 \sigma$ uncertainties (Table 2 ), as is generally found among molecules from studies of previous comets. This is consistent with electrons and fast $\mathrm{H}$-atoms, released primarily 

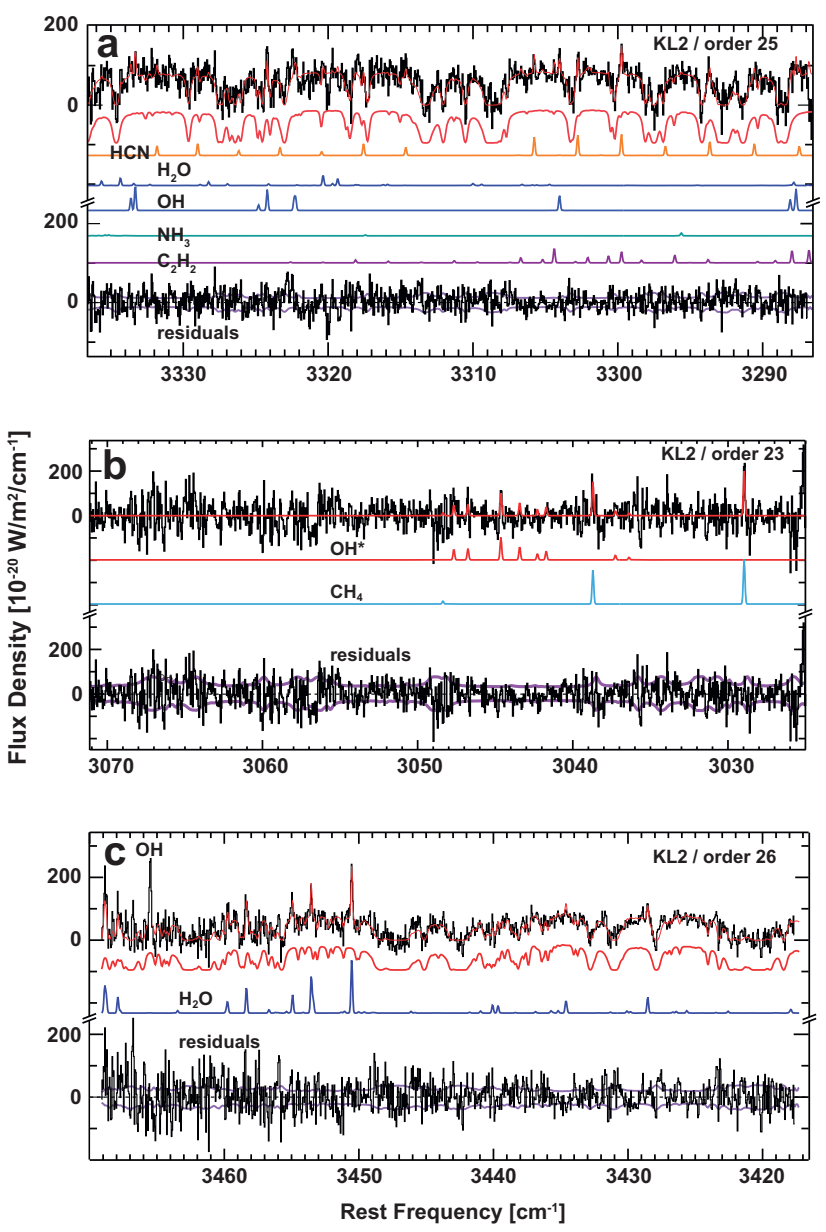

Fig. 3. Same as Figs. 1 and 2, but for January 8 .

through photo-dissociation of $\mathrm{H}_{2} \mathrm{O}$, controlling $T_{\text {rot }}$ in the coma (see Xie and Mumma, 1996; DiSanti et al., 2001 and references therein). It may also explain the similar $T_{\text {rot }}$ (also within $1 \sigma$ ) measured postperihelion for $\mathrm{H}_{2} \mathrm{O}$, for example if the smaller $R_{h}$ on January 8 was compensated by the lower water production rate $Q\left(\mathrm{H}_{2} \mathrm{O}\right)$. Our lower post-perihelion $Q\left(\mathrm{H}_{2} \mathrm{O}\right)$ is consistent with pre-/post-perihelion asymmetries found by other observers of C/2009 P1 (Section 4.3), and holds regardless of the exact values we adopt for $T_{\text {rot, }}$ both on October 13 and January 8 (see Section 3.2.1).

\subsection{Production rates}

Our formalism for determining production rates is based on the spatial distribution of emissions along the slit (i.e., the spatial profiles; Fig. 4) and is well documented in the literature (e.g., Villanueva et al., 2011a; Bonev, 2005). A brief summary is provided here.

We calculate a nucleus-centered molecular production rate $\left(Q_{n c}\right)$ from signal contained in the central nine spatial pixels centered on the peak emission intensity. For a given emission line (or, in the case of blends, for each group of lines):

$Q_{\text {nc,line }}=\frac{4 \pi \Delta^{2}}{\tau_{1} f(x)} \frac{F_{\text {line }}}{g_{\text {line }}}$

In Eq. (1), $\tau_{1}(\mathrm{~s})$ and $g_{1}\left(\mathrm{~W}\right.$ molecule $\left.{ }^{-1}\right)$ represent the photo-dissociation lifetime and fluorescence g-factor (both evaluated at $R_{h}=1 \mathrm{AU}$ ), $F_{\text {line }}\left(\mathrm{W} \mathrm{m}^{-2}\right)$ is the line flux at the top of the terrestrial atmosphere, and geocentric distance $(\Delta)$ is expressed in meters. For each molecular species, the quantity $f(x)$ represents the fraction of all molecules in the coma contained in the beam assuming release solely from the nucleus (i.e., purely native release). It is a geometrical parameter that decreases with increasing distance from the nucleus and depends on $R_{h}, \Delta$, and gas outflow speed $v_{\text {gas }}$, assumed to be spherically-symmetric and equal to $800 R_{h}^{-0.5} \mathrm{~m} \mathrm{~s}^{-1}$ (Biver et al., 2006, ${ }^{3}$ 2002). Because $f(x)$ varies approximately as $\tau_{1}^{-1}$ for our field of view, our production rates are relatively insensitive to assumed photo-dissociation lifetime (e.g., see DiSanti et al., 2001). In practice $Q_{n c}$ for a molecule is the mean of its line-by-line nucleus-centered production rates weighted by their individual stochastic errors.

For each molecule having emission with sufficient signal-tonoise, we then calculate the production rate at regular intervals (steps) along the slit (i.e., along the spatial profile) using Eq. (1), based on the encompassed $F_{\text {line }}$ and incorporating the value of $f(x)$ at each step. Outside the seeing-dominated inner coma, the production rates so determined increase to a constant value (within noise) that we take to be the terminal (or total) production rate $\left(Q_{\text {tot }}\right)$. This establishes a "growth factor" (GF) as the ratio $Q_{\text {tot }} / Q_{\text {nc }}$ (e.g., see Appendix B2 in Bonev et al., 2006, and Dello Russo et al., 1998 for details regarding the " $Q$-curve" formalism), or:

$Q_{\text {tot }}=Q_{\mathrm{nc}} * \mathrm{GF}$.

We generally find growth factors among simultaneously-measured primary volatiles to agree within uncertainties. For this reason we adopt a common value, given by the weighted mean of measured growth factors for all (native) species within each given setting (see Section 3.2.1). However, release of molecules in the coma can result in larger growth factors. In Section 3.3 we discuss the influence of an additional, extended source of $\mathrm{H}_{2} \mathrm{O}$ on October 13 .

\subsubsection{Dependence of production rates on $T_{\text {rot }}$ and GF}

We obtained consistent production rates whether we used a common rotational temperature or each individually measured $T_{\text {rot }}$ (see note 'b' of Table 2). Including $\sigma T_{\text {rot }}$ increases uncertainties in $Q_{\text {nc }}$ (listed in parentheses), and using individually measured $\sigma T_{\text {rot }}$ likely overestimated $\sigma Q_{\mathrm{nc}}$ since their $T_{\text {rot }}$ were less well constrained. For this reason, and because $T_{\text {rot }}$ was not measured for all species, we take $\sigma Q_{\text {nc }}$ (and $\sigma Q_{\text {tot }}$ ) based on the "combined" $\sigma T_{\text {rot }}$ ( $\pm 4 \mathrm{~K}$ on October 13 ) to provide the most consistent measure of molecular production rates.

The influence of growth factor is also summarized in Table 2. We found no evidence that any molecules other than $\mathrm{H}_{2} \mathrm{O}$ on October 13 were subject to effects other than atmospheric seeing. Since seeing-related flux loss is a common systematic effect within a given setting, we used the same GF for all co-measured species except $\mathrm{H}_{2} \mathrm{O}$ on October 13 . For KL1 we applied the weighted mean GF from $\mathrm{C}_{2} \mathrm{H}_{6}$ and $\mathrm{CH}_{3} \mathrm{OH}$, emphasizing that their growth factors agree well within error. Similarly, for KL2 we used the weighted mean GF from $\mathrm{HCN}$ and $\mathrm{CH}_{4}$ on October 13 , and that from $\mathrm{HCN}$, $\mathrm{CH}_{4}$, and $\mathrm{H}_{2} \mathrm{O}$ on January 8 . On the other hand, in addition to seeing the spatial distribution for $\mathrm{H}_{2} \mathrm{O}$ on October 13 was seemingly influenced by release from a source in the coma, as evidenced by its larger growth factors. In summary, for all molecules, both their production rates and abundances relative to $\mathrm{H}_{2} \mathrm{O}$ were insensitive to individually measured rotational temperatures or (excepting $\mathrm{H}_{2} \mathrm{O}$ on October 13) growth factors.

\subsection{Significance of spatial profiles in assessing volatile release}

Comparing spatial profiles permits testing the nature of release of individual volatile species and dust. Fig. 4 shows emission profiles from October 13 and January 8 for each molecular species

\footnotetext{
3 The best-fit heliocentric dependence of $v_{\text {gas }}$ for the 4 comets in Biver et al. (2006) is $R_{h}{ }^{-0.53 \pm 0.12} \mathrm{~km} \mathrm{~s}^{-1}$.
} 
Table 2

Volatile composition of C/2009 P1.

\begin{tabular}{|c|c|c|c|c|c|}
\hline Molec. & $T_{\text {rot }}{ }^{a}(\mathrm{~K})$ & $Q_{\mathrm{nc}}^{\mathrm{b}}\left(10^{25} \mathrm{~s}^{-1}\right)$ & $\mathrm{GF}^{\mathrm{c}}$ & $Q_{\text {tot }}{ }^{\mathrm{d}}\left(10^{25} \mathrm{~s}^{-1}\right)$ & $\mathrm{X} / \mathrm{H}_{2} \mathrm{O}(\%)^{\mathrm{e}}$ \\
\hline \multicolumn{6}{|c|}{ Pre-perihelion - UT 2011 October 13} \\
\hline \multicolumn{6}{|c|}{ KL2 setting } \\
\hline $\mathrm{H}_{2} \mathrm{O}$ & $(48 \pm 4)$ & $4640 \pm 312(352)$ & $1.94 \pm 0.069$ & $8980 \pm 752$ & 100 \\
\hline \multirow[t]{3}{*}{$\mathrm{HCN}$} & $48 \pm 4$ & $14.4 \pm 0.84(0.95)$ & $1.498 \pm 0.071$ & $21.5 \pm 1.76$ & $0.236 \pm 0.018$ \\
\hline & $55^{+6} /-7$ & $13.3 \pm 0.99(1.45)$ & & $20.0 \pm 2.37$ & $0.219 \pm 0.0307$ \\
\hline & $55^{+6} /-7$ & $13.3 \pm 0.99(1.45)$ & $1.497 \pm 0.086$ & $20.0 \pm 2.42$ & $0.219 \pm 0.0312$ \\
\hline \multirow[t]{3}{*}{$\mathrm{CH}_{4}$} & $48 \pm 4$ & $52.9 \pm 2.40(6.07)$ & $1.498 \pm 0.071$ & $79.2 \pm 9.84$ & $0.882 \pm 0.089$ \\
\hline & $50 \pm 10$ & $55.7 \pm 2.53(14.3)$ & & $83.4 \pm 21.8$ & $0.913 \pm 0.249$ \\
\hline & $50 \pm 10$ & $55.7 \pm 2.53(14.3)$ & $1.501 \pm 0.148$ & $83.6 \pm 23.0$ & $0.914 \pm 0.261$ \\
\hline $\mathrm{H}_{2} \mathrm{CO}$ & $(48 \pm 4)$ & $6.53 \pm 2.37(2.38)$ & $(1.498 \pm 0.071)$ & $9.78 \pm 3.60$ & $0.11 \pm 0.041$ \\
\hline $\mathrm{NH}_{3}$ & $(48 \pm 4)$ & $29.7 \pm 9.30(9.56)$ & $(1.498 \pm 0.071)$ & $44.5 \pm 14.5$ & $0.50 \pm 0.16$ \\
\hline $\mathrm{C}_{2} \mathrm{H}_{2}$ & $(48 \pm 4)$ & $3.36 \pm 1.32(1.32)$ & $(1.498 \pm 0.071)$ & $5.03 \pm 1.99$ & $0.056 \pm 0.023$ \\
\hline \multicolumn{6}{|c|}{ MwideA setting } \\
\hline $\mathrm{H}_{2} \mathrm{O}$ & $(48 \pm 4)$ & $5200 \pm 1680(1690)$ & $1.83 \pm 0.126$ & $9540 \pm 3150$ & 100 \\
\hline \multirow[t]{2}{*}{$\mathrm{CO}$} & $48 \pm 4$ & $565 \pm 26.6(35.9)$ & $1.52 \pm 0.056$ & $860 \pm 63.0$ & $9.12 \pm 0.80^{f}$ \\
\hline & $48^{+10} /-9$ & $565 \pm 26.6(63.2)$ & & $860 \pm 101$ & $9.12 \pm 1.22^{\mathrm{f}}$ \\
\hline \multicolumn{6}{|c|}{ KL1 setting } \\
\hline $\mathrm{H}_{2} \mathrm{O}$ & $(48 \pm 4)$ & $6250 \pm 566(579)$ & $1.680 \pm 0.085$ & $10,600 \pm 1100$ & 100 \\
\hline \multirow[t]{3}{*}{$\mathrm{C}_{2} \mathrm{H}_{6}$} & $48 \pm 4$ & $45.9 \pm 2.43(3.79)$ & $1.482 \pm 0.085$ & $68.1 \pm 5.61$ & $0.644 \pm 0.098$ \\
\hline & $44^{+9} /-7$ & $44.7 \pm 2.32(4.29)$ & & $66.2 \pm 6.36$ & $0.621 \pm 0.100$ \\
\hline & $44^{+9} /-7$ & $44.7 \pm 2.32(4.29)$ & $1.480 \pm 0.090$ & $66.1 \pm 6.48$ & $0.626 \pm 0.102$ \\
\hline \multirow[t]{3}{*}{$\mathrm{CH}_{3} \mathrm{OH}$} & $48 \pm 4$ & $153 \pm 15.6(15.7)$ & $1.482 \pm 0.085$ & $226 \pm 26.6^{g}$ & $2.14 \pm 0.38$ \\
\hline & $45^{+6} /-5$ & $151 \pm 15.5(15.7)$ & & $224 \pm 26.3$ & $2.12 \pm 0.38$ \\
\hline & $45^{+6} /-5$ & $151 \pm 15.5(15.7)$ & $1.501 \pm 0.266$ & $232 \pm 51.1$ & $2.15 \pm 0.52$ \\
\hline \multirow{2}{*}{\multicolumn{6}{|c|}{$\begin{array}{l}\text { Post-perihelion - UT } 2012 \text { January } 8 \\
\text { KL2 setting }\end{array}$}} \\
\hline & & & & & \\
\hline \multirow[t]{2}{*}{$\mathrm{H}_{2} \mathrm{O}$} & $55 \pm 10$ & $4907 \pm 185(546)$ & $1.478 \pm 0.131$ & $7253 \pm 698$ & 100 \\
\hline & $55 \pm 10$ & $4907 \pm 185(546)$ & $1.459 \pm 0.178$ & $7159 \pm 1183$ & 100 \\
\hline \multirow[t]{2}{*}{$\mathrm{HCN}$} & $(55 \pm 10)$ & $9.2 \pm 0.90(1.83)$ & $1.478 \pm 0.131$ & $13.6 \pm 1.79$ & $0.19 \pm 0.020$ \\
\hline & $(55 \pm 10)$ & $9.2 \pm 0.90(1.83)$ & $1.569 \pm 0.269$ & $14.4 \pm 3.79$ & $0.20 \pm 0.063$ \\
\hline \multirow[t]{2}{*}{$\mathrm{CH}_{4}$} & $(55 \pm 10)$ & $35.7 \pm 7.35(11.5)$ & $1.478 \pm 0.131$ & $52.8 \pm 11.8$ & $0.73 \pm 0.152$ \\
\hline & $(55 \pm 10)$ & $35.7 \pm 7.35(11.5)$ & $1.428 \pm 0.277$ & $51.0 \pm 19.2$ & $0.71 \pm 0.293$ \\
\hline $\mathrm{H}_{2} \mathrm{CO}$ & $(55 \pm 10)$ & $<4.9(3 \sigma)$ & $(1.478 \pm 0.131)$ & $<7.2$ & $<0.10(3 \sigma)$ \\
\hline $\mathrm{NH}_{3}$ & $(55 \pm 10)$ & $<35.7(3 \sigma)$ & $(1.478 \pm 0.131)$ & $<52.8$ & $<0.73(3 \sigma)$ \\
\hline $\mathrm{C}_{2} \mathrm{H}_{2}$ & $(55 \pm 10)$ & $<3.8(3 \sigma)$ & $(1.478 \pm 0.131)$ & $<5.6$ & $<0.077(3 \sigma)$ \\
\hline
\end{tabular}

a Relatively precise rotational temperatures were measured for five primary volatiles on October $13\left(\mathrm{HCN}, \mathrm{CH}_{4}, \mathrm{CO}_{2} \mathrm{C}_{2} \mathrm{H}_{6}\right.$, and $\left.\mathrm{CH}_{3} \mathrm{OH}\right)$. Their weighted mean $(48 \pm 4 \mathrm{~K}$,

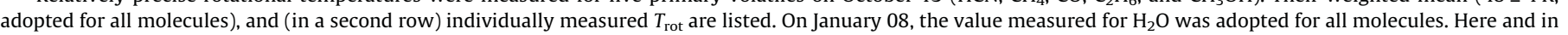

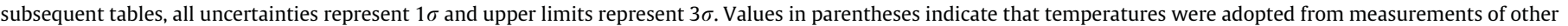
molecules.

b Nucleus centered production rate. For each entry, the first uncertainty corresponds to the larger of the stochastic or standard error among lines sampled, and the second entry (in parentheses) incorporates uncertainty in $T_{\text {rot. }}$ Production rates for individually measured $T_{\text {rot }}$ are also listed (second row).

c Scaling factor (growth factor, GF) for $Q$ outside the seeing-dominated region, relative to $Q_{\mathrm{nc}}$. Values in parentheses indicate that GF was adopted from measurements of other molecules.

d Total production rate (Eq. (2)). For each molecule, the uncertainty includes both those in mean GF and $T_{\text {rot, }}$ with GF from October 13 based on $\mathrm{HCN}$ and $\mathrm{CH}_{4}$ in $\mathrm{KL}_{2}$, and on

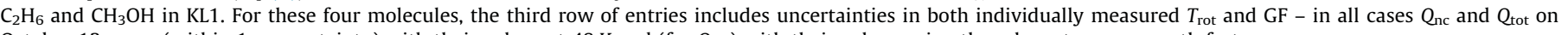
October 13 agree (within $1 \sigma$ uncertainty) with their values at $48 \mathrm{~K}$ and (for $Q_{\text {tot }}$ ) with their values using the relevant mean growth factors.

e Abundance, corresponding to the ratio of molecular production rates $Q_{\text {tot }} / Q_{\text {tot }}\left(\mathrm{H}_{2} \mathrm{O}\right)$. All molecules are assumed to have the same $T_{\text {rot }}$, hence both pre- and post-perihelion, $\sigma T_{\text {rot }}$ is not included in determining our "most probable" abundances (shown in bold). On October 13, uncertainties in GF are included since emissions span multiple settings.

${ }^{\mathrm{f}} \mathrm{CO}$ abundance, compared to the weighted mean global production rate for $\mathrm{H}_{2} \mathrm{O}$ among the three settings on October $13\left(=9430 \pm 606 \times 10^{25}\right.$ molecules $\left.\mathrm{s}^{-1}\right)$, at $T_{\text {rot }}=48 \pm 4 \mathrm{~K}$ (first row) and at the $T_{\text {rot }}$ measured for CO.

$\mathrm{g}$ The production rate listed for $\mathrm{CH}_{3} \mathrm{OH}$ is the weighted mean of those from orders $22\left(232 \pm 32 \times 10^{25}\right.$ molecules s $\left.\mathrm{s}^{-1}\right)$ and $23\left(216 \pm 39 \times 10^{25}\right.$ molecules s$\left.{ }^{-1}\right)$.

(heavy trace in each panel), the dust continuum profile (light trace, co-measured within each order), and a representative pointspread-function (PSF, dotted trace) based on the measured stellar profile. In each order, the continuum profile defines the zero position for projected distance along the slit, and although distinct from co-measured molecular emission profiles as is generally the case for comets, it ensures uniform spatial registration for all targeted species. It also provides a reference position for extracting spectra and establishing nucleus-centered line intensities for species that lack a meaningful spatial profile owing to insufficient signal-to-noise, i.e., for $\mathrm{H}_{2} \mathrm{CO}, \mathrm{C}_{2} \mathrm{H}_{2}$, and $\mathrm{NH}_{3}$, both on October 13 and January 8.

The spatial profiles for $\mathrm{H}_{2} \mathrm{O}$ on October 13 were clearly broader than those of other molecules, hence their larger growth factors. This suggests the presence of two ice phases, polar (i.e., water-rich) and a-polar (CO-rich), as was discussed previously based on highresolution IR spectra of C/2009 P1 (Paganini et al., 2012; Villanueva et al., 2012c; see Section 4.4, and Appendix A). We note that the GF for $\mathrm{H}_{2} \mathrm{O}$ in $\mathrm{KL} 2$ was larger than that in $\mathrm{KL} 1$ (compare water profiles in Figs. 4a and 4e). This could indicate a change in the projected (line-of-sight) position of $\mathrm{H}_{2} \mathrm{O}$-rich (polar) grains in the coma and included within our (narrow) slit. It may or may not be associated with the reported nucleus rotation period of $10.4 \mathrm{~h}$ based on postperihelion observations of C/2009 P1 with DIXI/MRI on three UT dates spanning $R_{h}=1.7-2.1 \mathrm{AU}$ (Bodewits et al., 2012). ${ }^{4}$

For $\mathrm{H}_{2} \mathrm{O}$ in the MWA setting, we adopt the mean growth factor from KL1 and KL2, since we could not obtain a meaningful spatial profile due to insufficient signal-to-noise for water lines in this setting (see Fig. 1a). The MWA observations were conducted (temporally) between KL2 and KL1 (Table 1), so this approach should be reasonably representative of any evolution in water release (as projected in our slit) over the course of our October 13 observa-

\footnotetext{
4 If in a "complex" rotation state, the actual period for C/2009 P1 would be a multiple of the reported 10 -h period.
} 

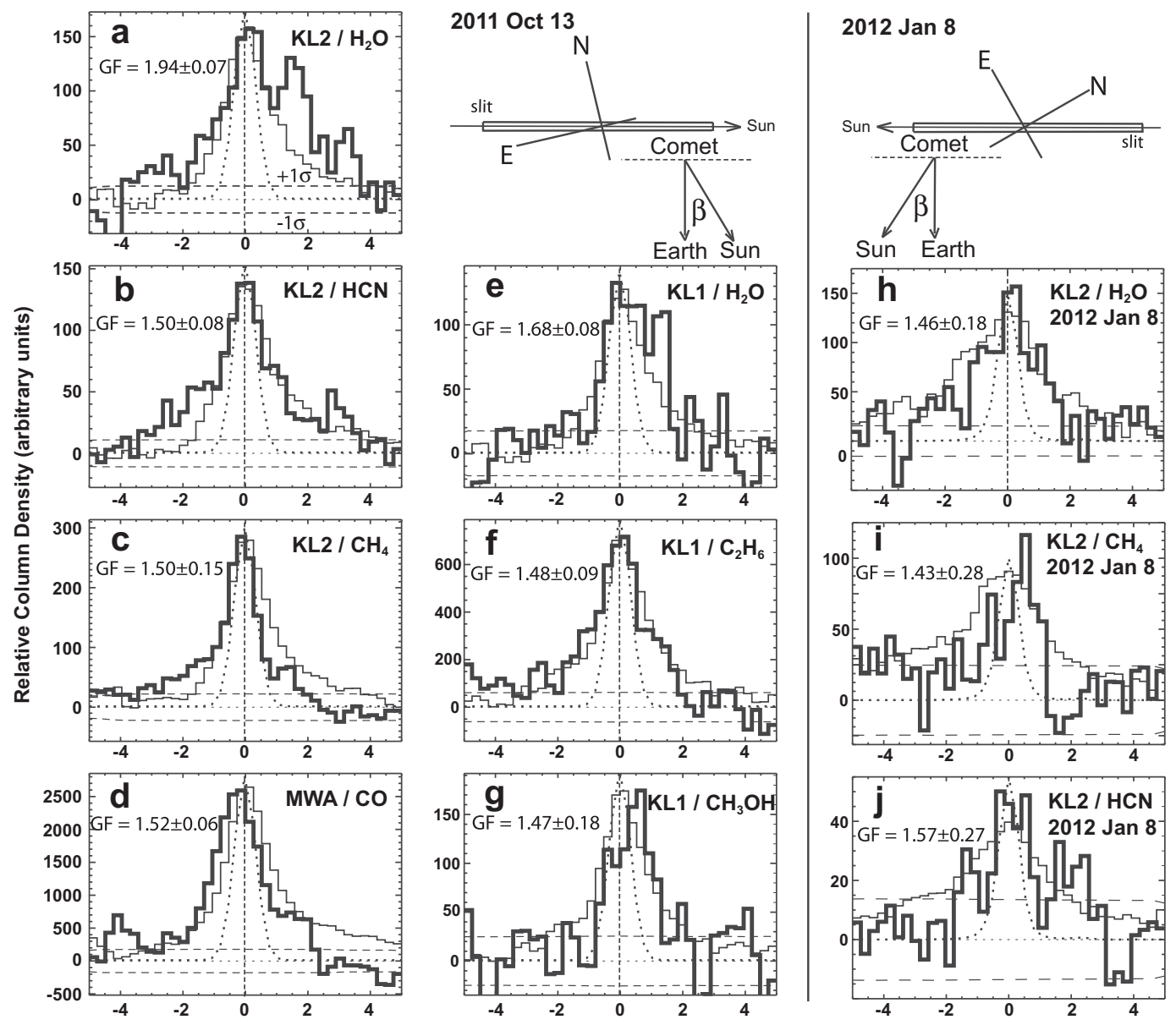

Projected Distance from Nucleus $\left(10^{3} \mathrm{~km}\right)$

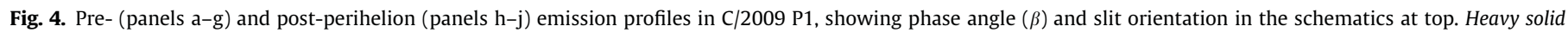

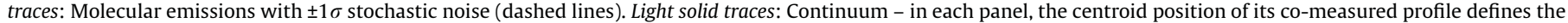

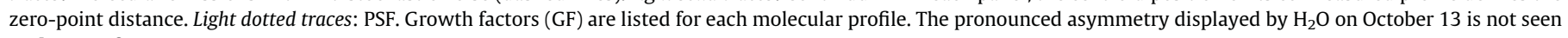
on January 8.

tions. The value of $Q_{\text {tot }}$ for $\mathrm{H}_{2} \mathrm{O}$ in MWA is consistent with those in KL1 and KL2, albeit with larger uncertainty.

C/2009 P1 is the third recent comet to show evidence for (at least) two distinct phases of ice within the nucleus, one dominated by polar ice and the other by a-polar ice. In C/2007 W1 (Boattini), the polar molecules $\mathrm{H}_{2} \mathrm{O}$ and $\mathrm{CH}_{3} \mathrm{OH}$ showed asymmetric profiles in the anti-sunward hemisphere, and a source of small particles composed of relatively pure polar (water-rich) ice was proposed (Villanueva et al., 2011a). Comet 103P/Hartley-2 showed symmetric $\mathrm{H}_{2} \mathrm{O}$ and $\mathrm{CH}_{3} \mathrm{OH}$ profiles, while $\mathrm{C}_{2} \mathrm{H}_{6}$ was strongly asymmetric and $\mathrm{HCN}$ was intermediate (Mumma et al., 2011). Although a polar molecule the distribution of $\mathrm{HCN}$ was closer to that of $\mathrm{C}_{2} \mathrm{H}_{6}$ in both C/2007 W1 and 103P, suggesting a source associated primarily with the a-polar ice contained in the nucleus. This also appears to be the case with $\mathrm{C} / 2009 \mathrm{P} 1$.

In contrast, on January 8 the water profile showed no such evidence of a bimodal distribution, and its growth factor was consistent with those measured for $\mathrm{CH}_{4}$ and $\mathrm{HCN}$ (Fig. 4h-j) and with release solely from the nucleus. For this reason we adopted the weighted mean GF for $\mathrm{H}_{2} \mathrm{O}, \mathrm{CH}_{4}$, and $\mathrm{HCN}$ (1.48 \pm 0.13 ; Table 2) for all co-measured volatiles on January 8. Both $\mathrm{H}_{2} \mathrm{O}$ and $\mathrm{CH}_{4}$ peaked slightly anti-sunward of the continuum, however their noise levels make it difficult to determine if any displacement is significant. We present additional pre-/post-perihelion comparisons in Section 4.3.

\section{Comparisons among C/2009 P1 observations}

\subsection{Compositional comparison with other infrared observations}

Fig. 5 shows a comparison of our abundance ratios with those obtained near 2.1 and 2.0 AU (Villanueva et al., 2012c; Paganini et al., 2012, respectively), relative to $\mathrm{H}_{2} \mathrm{O}$ (Fig. 5a; Table 2) and $\mathrm{HCN}$ (Fig. 5b; Table 3). Those studies found growth factors of 1.8 for $\mathrm{H}_{2} \mathrm{O}$ and 1.4 for other species, similar to those we found here. Our abundances on October 13 (at $R_{h}=1.83 \mathrm{AU}$ pre-perihelion) are consistent with those reported approximately 1 month earlier (near $R_{h}=2.1 \mathrm{AU}$; Villanueva et al., 2012c) for $\mathrm{HCN}, \mathrm{CH}_{4}, \mathrm{NH}_{3}$, and $\mathrm{C}_{2} \mathrm{H}_{6}$ (using NIRSPEC) and for CO (using CSHELL), whether expressed relative to $\mathrm{H}_{2} \mathrm{O}$ or $\mathrm{HCN}$. Our retrieved abundances relative to $\mathrm{H}_{2} \mathrm{O}$ are systematically lower than those reported for $\mathrm{CO}, \mathrm{CH}_{3} \mathrm{OH}, \mathrm{CH}_{4}, \mathrm{C}_{2} \mathrm{H}_{6}$, and $\mathrm{HCN}$ from CRIRES observations near 2.0 AU, however it was pointed out (Paganini et al., 2012) that adopting the value for $\mathrm{Q}\left(\mathrm{H}_{2} \mathrm{O}\right)$ from optical observations of OH (Section 4.2) brings the CRIRES results into the "normal" range (see Section 5). Perhaps the outgassing pattern (particularly of $\mathrm{H}_{2} \mathrm{O}$ ) was changing with time, as suggested by comparisons among spatial profiles from infrared observations (e.g., compare Fig. 4a and e, and see Section 4.4). This could lead to abundance ratios relative to $\mathrm{H}_{2} \mathrm{O}$ that are sensitive to rotational phase and slit geometry. Our measured abundances relative to HCN (Fig. 5b; Table 3 ) show much better agreement with the CRIRES results. 


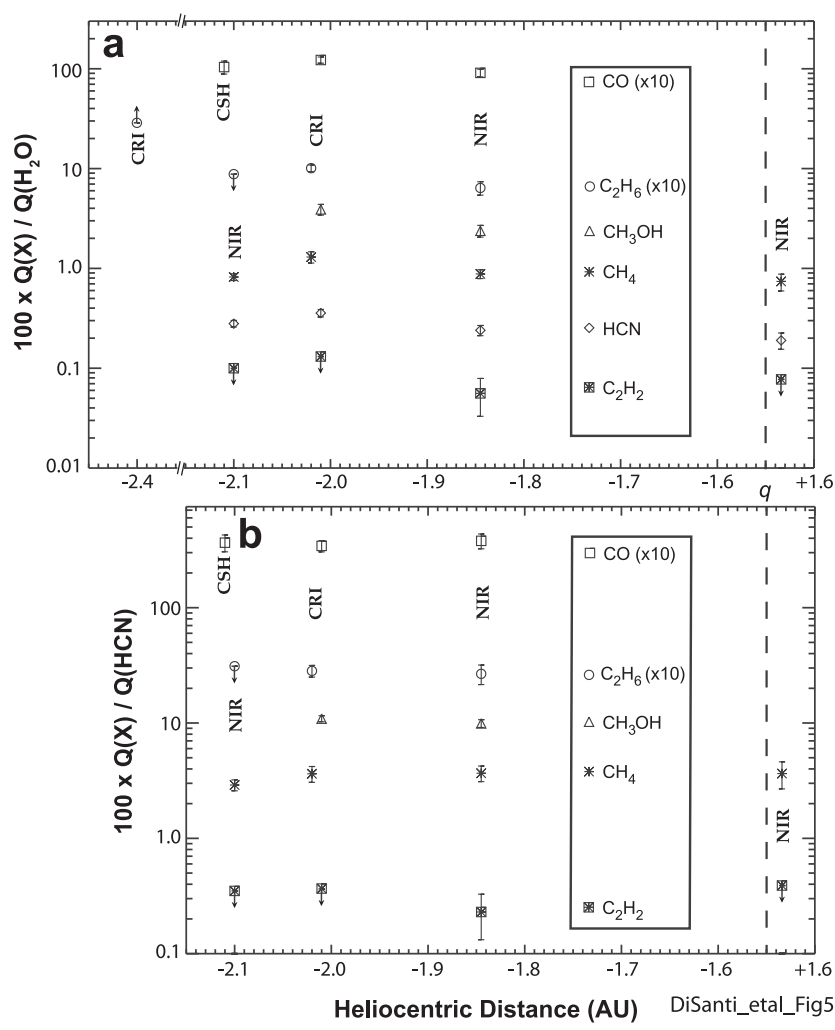

Fig. 5. Abundances of several primary volatiles in C/2009 P1 (Garradd), expressed in percent relative to $\mathrm{H}_{2} \mathrm{O}$ (panel a) and $\mathrm{HCN}$ (panel b) and retrieved using highresolution IR spectroscopy. Note that for clarity, the points for $\mathrm{CO}$ and $\mathrm{C}_{2} \mathrm{H}_{6}$ are offset by a factor of 10 relative to their measured values. Error bars denote $\pm 1 \sigma$ and upper limits (denoted by downward-facing arrows) are $3 \sigma$. Perihelion ( $q=1.5505 \mathrm{AU})$ is indicated by vertical dashed lines, and negative heliocentric distances denote pre-perihelion dates. Points (or groups of points) are labeled with instrument used: NIR = NIRSPEC/Keck II, CSH $=$ CSHELL/IRTF, CRI = CRIRES/VLT. Measurements near $R_{\mathrm{h}}=-2.1 \mathrm{AU}$ are from Villanueva et al. (2012c), and those near -2.4 and $-2.0 \mathrm{AU}$ are from Paganini et al. (2012). The lower limit for the abundance of $\mathrm{C}_{2} \mathrm{H}_{6}$ at $-2.4 \mathrm{AU}$ corresponds to the upper limit $(3 \sigma)$ found for $\mathrm{H}_{2} \mathrm{O}$, which had not yet fully activated at that heliocentric distance.

\subsection{Comparison with optical observations of C/2009 P1}

D. Schleicher (private communication, 2011) reported water production rates $\left(1.5 \times 10^{29}\right.$ molecules $\left.\mathrm{s}^{-1}\right)$ from narrow-band photometry at $R_{h}=1.97 \mathrm{AU}$ (September 24) and $1.80 \mathrm{AU}$ (October 18 and 20) that are approximately 50\% larger than the values reported from the IR studies (Paganini et al., 2012; Villanueva et al., 2012c, and our $Q_{\text {tot }}$ for $\mathrm{H}_{2} \mathrm{O}$ on October 13). This suggests release of additional water not encompassed by the (very narrow) IR slits.

\subsection{Pre-/post-perihelion comparisons}

Six of nine primary volatiles measured in C/2009 P1 on October 13 were also measured on January 8. Abundance ratios of $\mathrm{HCN}$ and
$\mathrm{CH}_{4}$ (relative to $\mathrm{H}_{2} \mathrm{O}$ ) were unchanged (within $1 \sigma$ uncertainties), and upper limits $(3 \sigma)$ for $\mathrm{H}_{2} \mathrm{CO}, \mathrm{NH}_{3}$, and $\mathrm{C}_{2} \mathrm{H}_{2}$ on January 8 were also consistent with their measured values on October 13. Cometary nuclei are thought to be processed to depths of tens of centimeters during their residence time in the Oort cloud, primarily through irradiation by interstellar cosmic rays (Stern, 2003; also see Mumma et al., 1993). A typical comet loses approximately $1 \mathrm{~m}$ from its surface per perihelion passage - for dynamically new comets this could lead to pre-/post-perihelion compositional differences resulting from surface erosion of irradiated layers. Regardless of the dynamical status of C/2009 P1 (dynamically new or long-period returning), the agreement between pre- and post-perihelion abundance ratios suggests, for the active region(s) and to the depths sampled, compositional homogeneity among measured ices that may reflect its primordial endowment.

A notable result is that the overall gas production in C/2009 P1 was lower on January 8 despite being closer to perihelion: $Q_{\text {tot }}$ for $\mathrm{H}_{2} \mathrm{O}$ was lower by $\sim 23 \%$ relative to its mean value among settings on October 13 (Table 2, see note ' $\mathrm{f}$ ). Subsequent observations of C/2009 P1 by EPOXI/MRI on UT 2012 February $23\left(R_{h}=1.7 \mathrm{AU}\right)$ and April $06\left(R_{h}=2.1 \mathrm{AU}\right)$ yielded values for $Q(\mathrm{OH})$ (2.3 and $1.4 \times 10^{28}$ molecules s ${ }^{-1}$, respectively; Bodewits et al., 2012) that indicated a pronounced post-perihelion decrease in activity, at least in water production. SOHO/SWAN observations showed a steep $\left(R_{h}^{-3.2}\right)$ post-perihelion decrease in $Q\left(\mathrm{H}_{2} \mathrm{O}\right)$. This followed larger, relatively constant pre-perihelion production of $\mathrm{H}_{2} \mathrm{O}$ from $R_{h} \approx 2.1$ to $1.6 \mathrm{AU}$ (Combi et al., 2012) that was approximately three times our measured water production on October 13, consistent with additional release of $\mathrm{H}_{2} \mathrm{O}$ in the much larger SOHO field-of-view and again suggesting aperture-dependent pre-perihelion water production. The lack of a "water excess" in our January 8 observations (compare Fig. 4h with Figs. 4a and 4e, and see Section 4.4) suggests loss of one or more active regions, perhaps due to seasonal changes in pole orientation affecting insolation received locally on the nucleus. The agreement among our pre- and post-perihelion abundance ratios (Table 2) is also consistent with loss of one or more sources releasing volatiles directly from the nucleus along with extended release of $\mathrm{H}_{2} \mathrm{O}$, such that the production rates of $\mathrm{H}_{2} \mathrm{O}$ and measured trace species decreased by similar amounts.

\subsection{Comparison of spatial profiles - establishing pre-perihelion "excess" $\mathrm{H}_{2} \mathrm{O}$ emission}

On October 13, the weighted mean intensities for both $\mathrm{H}_{2} \mathrm{O}$ and $\mathrm{CH}_{3} \mathrm{OH}$ were in the sunward-facing hemisphere (Fig. 4), yet only $\mathrm{H}_{2} \mathrm{O}$ revealed a pronounced excess intensity that peaked between 1300 and $1500 \mathrm{~km}$ sunward as projected on the sky plane. A weaker secondary peak near +3000 to $+3500 \mathrm{~km}$ was also seen in the KL2 water profile. This approximate "distance doubling" of peaks in the water profile could be associated with the same grain source, for example if material released previously and tied to nucleus rotation was also responsible for the weaker peak. Alternatively this secondary peak could indicate an additional source of

Table 3

Abundance ratios relative to HCN in C/2009 P1 (Garradd) from IR spectroscopy. ${ }^{\text {a }}$

\begin{tabular}{|c|c|c|c|c|c|}
\hline Reference $\left(R_{\mathrm{h}}\right)^{\mathrm{b}}$ & $\mathrm{CO}$ & $\mathrm{C}_{2} \mathrm{H}_{6}$ & $\mathrm{CH}_{4}$ & $\mathrm{CH}_{3} \mathrm{OH}$ & $\mathrm{C}_{2} \mathrm{H}_{2}$ \\
\hline Villanueva et al. (2.1) & $37.1 \pm 6.7$ & $<3.14$ & $2.93 \pm 0.68$ & & $<0.36$ \\
\hline Paganini et al. (2.0) & $34.2 \pm 3.8$ & $2.81 \pm 0.32$ & $3.56 \pm 1.78$ & $10.8 \pm 1.73$ & $<0.36$ \\
\hline This work (1.8) & $38.0 \pm 4.6$ & $2.67 \pm 0.47$ & $3.67 \pm 0.48$ & $9.92 \pm 1.57$ & $0.23 \pm 0.10$ \\
\hline This work (1.6) & & & $3.64 \pm 1.03$ & & $<0.39$ \\
\hline
\end{tabular}

${ }^{\text {a }}$ Entries represent $100 \times Q(X) / Q(\mathrm{HCN})$ as shown in Fig. 5b, with uncertainties denoting $1 \sigma$ and upper limits denoting $3 \sigma$.

b Reference publication, and approximate heliocentric distance (AU, in parentheses). The first 3 rows in the table are pre-perihelion measurements, and the fourth row is post-perihelion. 
Table 4

Abundance ratios for reactants and products of $\mathrm{H}$-atom addition on interstellar grains.

\begin{tabular}{|c|c|c|c|c|c|c|}
\hline No. $^{\text {a }}$ & Comet $^{\mathrm{a}}$ & Origin $^{\mathrm{b}}$ & $\mathrm{CO} / \mathrm{H}_{2} \mathrm{O}^{\mathrm{a}}$ & $\mathrm{C}_{2} \mathrm{H}_{2} / \mathrm{H}_{2} \mathrm{O}^{\mathrm{a}}$ & $\mathrm{CH}_{3} \mathrm{OH} / \mathrm{H}_{2} \mathrm{O}^{\mathrm{a}, \mathrm{c}}$ & $\mathrm{C}_{2} \mathrm{H}_{6} / \mathrm{H}_{2} \mathrm{O}^{\mathrm{a}}$ \\
\hline 1 & C/2001 A2 (LINEAR) & $\mathrm{NIC} / \mathrm{OC}$ & $3.9 \pm 1.1^{d}$ & $0.5 \pm 0.1^{d}$ & $3.0 \pm 0.1^{d}$ & $1.7 \pm 0.2^{\mathrm{d}}$ \\
\hline 2 & C/1996 B2 (Hyakutake) & $\mathrm{NIC} / \mathrm{OC}$ & $14.9 \pm 1.9^{\mathrm{e}}$ & $0.16 \pm 0.08^{\mathrm{f}}$ & $1.7 \pm 0.4^{\mathrm{g}}$ & $0.62 \pm 0.07^{\mathrm{h}}$ \\
\hline 3 & C/1995 01 (Hale-Bopp) & $\mathrm{NIC} / \mathrm{OC}$ & $12.0 \pm 0.4^{\mathrm{i}}$ & $0.31 \pm 0.10^{\mathrm{j}}$ & $1.7 \pm 0.4^{\mathrm{k}}$ & $0.56 \pm 0.04^{1}$ \\
\hline 4 & C/1999 H1 (Lee) & $\mathrm{NIC} / \mathrm{OC}$ & $1.8 \pm 0.2^{\mathrm{m}}$ & $0.27 \pm 0.03^{\mathrm{m}}$ & $2.02 \pm 0.48^{\mathrm{m}}$ & $0.67 \pm 0.07^{\mathrm{m}}$ \\
\hline 5 & 153P/Ikeya-Zhang & HTC/OC & $4.7 \pm 0.8^{\mathrm{n}}$ & $0.18 \pm 0.05^{\circ}$ & $1.75 \pm 0.35^{\mathrm{n}}$ & $0.62 \pm 0.18^{\mathrm{p}}$ \\
\hline 6 & 1P/Halley & HTC/OC & $3.5^{\mathrm{q}}$ & $0.3^{\mathrm{q}}$ & $1.7 \pm 0.4^{\mathrm{r}}$ & $0.4^{\mathrm{q}}$ \\
\hline 7 & C/2004 Q2(Machholz) & $\mathrm{NIC} / \mathrm{OC}$ & $5.1 \pm 0.51^{\mathrm{s}}$ & $0.09 \pm 0.01^{\mathrm{s}}$ & $1.58 \pm 0.06^{\mathrm{s}}$ & $0.56 \pm 0.03^{s}$ \\
\hline 8 & $8 \mathrm{P} /$ Tuttle $^{\mathrm{H}}$ & HTC/OC & $0.45 \pm 0.09^{t}$ & $<0.04^{\mathrm{u}}$ & $1.94 \pm 0.10^{\mathrm{u}}$ & $0.25 \pm 0.03^{\mathrm{t}, \mathrm{u}}$ \\
\hline 9 & $\mathrm{C} / 2001 \mathrm{WM}_{1}$ (LINEAR) & $\mathrm{NIC} / \mathrm{OC}$ & $0.52 \pm 0.12^{\mathrm{v}}$ & $<0.05^{\mathrm{v}}$ & $1.12 \pm 0.07^{v}$ & $0.47 \pm 0.03^{v}$ \\
\hline 10 & C/1999 S4 (LINEAR) & $\mathrm{NIC} / \mathrm{OC}$ & $0.9 \pm 0.3^{w}$ & $<0.12^{\mathrm{w}}$ & $<0.18^{\mathrm{w}}$ & $0.11 \pm 0.02^{w}$ \\
\hline 11 & $73 \mathrm{P} / \mathrm{S}-\mathrm{W} 3-\mathrm{C}^{\mathrm{H}}$ & $\mathrm{JFC} / \mathrm{KB}$ & $0.5 \pm 0.13^{\mathrm{x}}$ & $0.23 \pm 0.06^{y},<0.033^{z}$ & $0.14 \pm 0.02^{z}$ & $0.18 \pm 0.03^{y, z}$ \\
\hline 12 & $103 \mathrm{P} /$ Hartley $2^{\mathrm{H}}$ & $\mathrm{JFC} / \mathrm{KB}$ & $0.15-0.45^{\mathrm{A}}$ & $0.110 \pm 0.011^{\mathrm{B}, \mathrm{C}}$ & $1.78 \pm 0.08^{\mathrm{B}, \mathrm{C}}$ & $0.73 \pm 0.03^{\mathrm{B}, \mathrm{C}}$ \\
\hline 13 & C/2007 N1 (Lulin) & $\mathrm{NIC} / \mathrm{OC}$ & $2.19 \pm 0.10^{\mathrm{D}}$ & $0.076 \pm 0.008^{\mathrm{D}}$ & $3.6 \pm 0.18^{\mathrm{D}}$ & $0.65 \pm 0.08^{\mathrm{D}}$ \\
\hline 14 & C/1999 T1(McNt-Hartley) & $\mathrm{NIC} / \mathrm{OC}$ & $17 \pm 4^{\mathrm{E}}$ & $0.13 \pm 0.03^{\mathrm{E}}$ & $3.0 \pm 0.3^{\mathrm{E}}$ & $0.67 \pm 0.033^{\mathrm{E}}$ \\
\hline 15 & C/2007 W3 (Boattini) & $\mathrm{NIC} / \mathrm{OC}$ & $4.5 \pm 0.51^{F}$ & $0.29 \pm 0.02^{\mathrm{F}}$ & $3.67 \pm 0.11^{\mathrm{F}}$ & $1.96 \pm 0.04^{\mathrm{F}}$ \\
\hline 16 & C/2009 P1 (Garradd) & $\mathrm{NIC} / \mathrm{OC}$ & $9.12 \pm 0.80^{G}$ & $0.056 \pm 0.023^{G}$ & $2.1 \pm 0.4^{\mathrm{G}}$ & $0.64 \pm 0.098^{G}$ \\
\hline
\end{tabular}

${ }^{a}$ ID numbers for comets refer to points in Fig. 6. Abundances are relative to $\mathrm{H}_{2} \mathrm{O}=100$.

b Present dynamical classification (NIC = Nearly Isotropic Comet, HTC = Halley Type Comet, JFC = Jupiter Family Ecliptic Comet) and likely storage reservoir (OC = Oort cloud, KB = Kuiper Belt).

${ }^{c}$ Previously published values for $Q\left(\mathrm{CH}_{3} \mathrm{OH}\right)$ from IR observations using the $v_{3} Q$-branch intensity have been inter-normalized to $g(Q$-br $)=1.5 \times 10^{-5}$ ph s ${ }^{-1}$ molecule ${ }^{-1}$ (Villanueva et al., 2012b).

d Magee-Sauer et al. (2008b).

e DiSanti et al. (2003).

f Magee-Sauer et al. (2002a).

$\mathrm{g}$ Biver et al. (1999a).

h Dello Russo et al. (2002a).

i DiSanti et al. (2001).

j Magee-Sauer et al. (1999).

k Biver et al. (1999b).

m Mumma et al. (2001b).

n DiSanti et al. (2002).

o Magee-Sauer et al. (2002b).

p Dello Russo et al. (2002b).

q Eberhardt (1999).

${ }^{\mathrm{r}}$ Eberhardt et al. (1994).

s Bonev et al. (2009).

t Böhnhardt et al., (2008)

u Bonev et al. (2008).

v Radeva et al. (2010).

w Mumma et al. (2001a).

x DiSanti et al. (2007).

y Villanueva et al. (2006).

z Dello Russo et al. (2007).

A Weaver et al. (2011).

B Dello Russo et al. (2011).

C Mumma et al. (2011).

D Gibb et al. (2012).

E Mumma et al. (2001c) and DiSanti et al. (in preparation);

F Villanueva et al. (2011a).

G This work.

${ }^{\mathrm{H}}$ For $8 \mathrm{P}, 73 \mathrm{P}$, and $103 \mathrm{P}$, entries having multiple references represent weighted mean values among cited papers.

water-rich grains having a larger characteristic scale for release of $\mathrm{H}_{2} \mathrm{O}$ in the sunward-facing hemisphere.

In contrast, $\mathrm{CH}_{4}, \mathrm{CO}, \mathrm{C}_{2} \mathrm{H}_{6}$, and $\mathrm{HCN}$ exhibited similar distributions, albeit with subtle differences: $\mathrm{CH}_{4}$ and $\mathrm{CO}$ peaked (slightly) toward the anti-sunward-facing hemisphere and showed slight degrees of asymmetry in that direction, perhaps indicating "night-side" release. $\mathrm{C}_{2} \mathrm{H}_{6}$ and $\mathrm{HCN}$ peaked coincident with the continuum and overall were more symmetric, however a statistically-significant excess in HCN emission was seen near $+3000 \mathrm{~km}$ (Fig. 4b), close in position to the simultaneously-measured secondary water peak in the KL2 setting (Fig. 4a). Our data do not permit discerning if these two features are related. Addressing this and related questions requires detailed knowledge of the nature and actual three dimensional distributions of sources, outflow, and release.

We estimated the fractional abundance of $\mathrm{H}_{2} \mathrm{O}$ attributable to the "excess" emission through comparison with the combined profiles of $\mathrm{C}_{2} \mathrm{H}_{6}$ and $\mathrm{HCN}$. We postulate its origin in $\mathrm{H}_{2} \mathrm{O}$-rich particles in the coma that contributed $25-30 \%$ of the total water within our slit (see Appendix A for details).

Evidence for excess $\mathrm{H}_{2} \mathrm{O}$ was also observed in C/2009 P1 using NIRSPEC on UT 2011 September 9 ( $\beta=26^{\circ}, R_{h}=2.1 \mathrm{AU}$; Villanueva et al., 2012c). For those observations, the slit was oriented approximately $45^{\circ}$ from the Sun-comet direction. The excess was most pronounced in the sunward-facing hemisphere (see Fig. $2 \mathrm{C}$ in Villanueva et al., 2012c) with a peak near projected distance $+1500 \mathrm{~km}$. A relatively smaller excess was seen on the opposite hemisphere, qualitatively consistent with our observations given the difference in slit orientations. A pronounced sun-side asymmetry was also seen in spectra of C/2009 P1 near $R_{h}=2.0 \mathrm{AU}$, using CRIRES with the slit along the projected Sun-comet direction (Paganini et al., 2012). Taken together, this suggests that the source region(s) on the nucleus giving rise to this excess $\mathrm{H}_{2} \mathrm{O}$ may have persisted and was/were illuminated similarly for at least the 


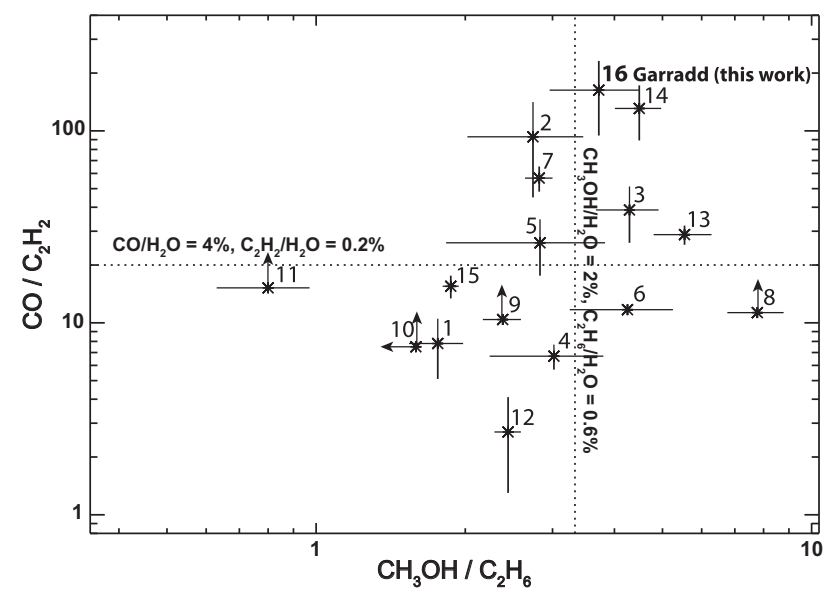

Fig. 6. Comparison of abundance ratios among comets (denoted by number in Table 4), related to processing of reactant $\left(\mathrm{CO}, \mathrm{C}_{2} \mathrm{H}_{2}\right)$, and product $\left(\mathrm{CH}_{3} \mathrm{OH}, \mathrm{C}_{2} \mathrm{H}_{6}\right)$ molecules through $\mathrm{H}$-atom addition (i.e., reduction) reactions on surfaces of interstellar grains. Vertical (horizontal) dotted lines indicate "normal" abundances (median value for $\mathrm{CO}$ ) as discussed in the text. For each point, $\pm 1 \sigma$ confidence limits are shown, and upward arrows indicate that only upper limits $(3 \sigma)$ were obtained for $\mathrm{C}_{2} \mathrm{H}_{2}$ (the arrow to the left on point 10 reflects the upper limit for $\mathrm{CH}_{3} \mathrm{OH}$ obtained for Comet S4 LINEAR). Of these comets, C/2009 Garradd (point 16) shows the highest $\mathrm{CO} / \mathrm{C}_{2} \mathrm{H}_{2}$ obtained to date, yet both its $\mathrm{C}_{2} \mathrm{H}_{6}$ and $\mathrm{CH}_{3} \mathrm{OH}$ are consistent with their normal values.

5-week period encompassing those observations and the ones on October 13 reported here.

\section{Taxonomy of primary volatile abundances: placing C/2009 P1 in context}

As a working hypothesis, comets can be classified "organics normal," "organics depleted," or "organics enriched," based on their abundances of the four organic molecules $\mathrm{C}_{2} \mathrm{H}_{6}, \mathrm{CH}_{3} \mathrm{OH}$, $\mathrm{HCN}$, and $\mathrm{C}_{2} \mathrm{H}_{2}$ relative to $\mathrm{H}_{2} \mathrm{O}$, with "normal" values being approximately $0.6 \%, 2 \%, 0.2 \%$, and $0.2 \%$, respectively (e.g., see Mumma and Charnley, 2011, and references therein). In C/2009 P1, the abundance ratios (relative to $\mathrm{H}_{2} \mathrm{O}$ ) we measured for $\mathrm{C}_{2} \mathrm{H}_{6}(0.64 \%$ ), $\mathrm{CH}_{3} \mathrm{OH}(2.1 \%)$, and $\mathrm{HCN}(0.24 \%)$ were consistent with "organicsnormal," however $\mathrm{C}_{2} \mathrm{H}_{2}(0.06 \%)$ was well below its normal value.

The abundance of $\mathrm{NH}_{3}(0.5 \%)$ fell within the range measured in comets (Magee-Sauer et al., 2008a), and $\mathrm{H}_{2} \mathrm{CO}(0.11 \%)$ was similar to that found in several comets (0.1-0.3\%); e.g., C/2004 Q2 (Mach-

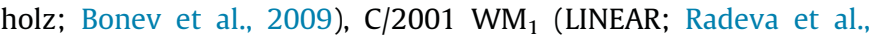
2010), and C/2007 N1 (Lulin; Gibb et al., 2012). It was however well below that found in C/2002 T7 (LINEAR; DiSanti et al., 2006) or C/2002 C1 (Ikeya-Zhang; DiSanti et al., 2002). Whether a "dichotomy" in (native) $\mathrm{H}_{2} \mathrm{CO} / \mathrm{H}_{2} \mathrm{O}$ (i.e., $>0.5 \%$, versus significantly below $0.5 \%$ ) extends to the overall comet population is an open question that can only be answered by measuring its abundance in the nuclei of a significantly larger number of comets.

Our abundance ratio $\mathrm{CH}_{4} / \mathrm{H}_{2} \mathrm{O}$ in $\mathrm{C} / 2009 \mathrm{P} 1$ (0.8-0.9\%) was close to its median value found among comets $(0.9-1 \%)$. Our measured abundance ratio for $\mathrm{CO}(9.1 \%)$ was within the range found in comets, which span $<0.5 \%$ (Weaver et al., 2011) to $\sim 30 \%$ (e.g., see Bockelée-Morvan et al., 2005), but significantly above its median value among comets ( 4\%). Only C/1996 B2 (Hyakutake; DiSanti et al., 2003), C/1995 O1 (Hale-Bopp; Bockelée-Morvan et al., 2009; DiSanti et al., 2001), and C/1999 T1 (McNaught-Hartley; Mumma et al., 2001c) had $\mathrm{CO} / \mathrm{H}_{2} \mathrm{O}$ exceeding $10 \%$. The abundance of $\mathrm{CO}$ in C/2009 P1 was also well above that found for the majority of comets observed within $R_{h}=2.5 \mathrm{AU}$ in the Akari survey (Ootsubo et al., 2012). This classifies C/2009 P1 as a CO-rich comet, as noted from other studies (Paganini et al., 2012; Villanueva et al., 2012c; Biver et al., 2012; McKay et al., 2012, Feaga et al., 2012).
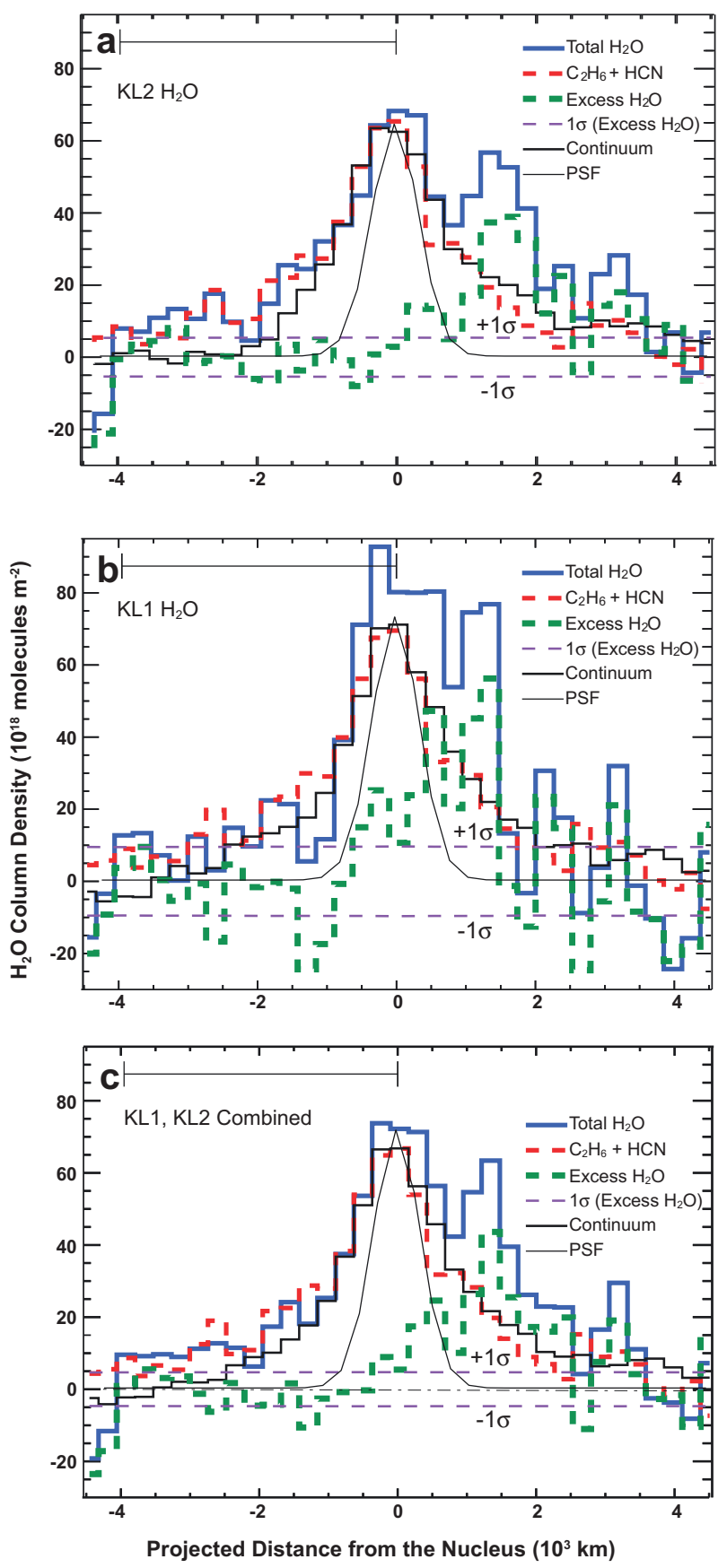

Fig. A1. Graphical illustration showing the methodology used to estimate the fraction of $\mathrm{H}_{2} \mathrm{O}$ released in the coma of C/2009 P1 (Garradd) on UT 2011 October 13 We take the $\mathrm{C}_{2} \mathrm{H}_{6}+\mathrm{HCN}$ profile as our representative (purely) native profile (see Section A.1).

\section{Redox chemistry of grain surface reactions}

6.1. Molecular abundances in comets as a possible test for redox chemistry

The combined reactions of condensed interstellar molecules (e.g., $\mathrm{CO}$ and $\mathrm{C}_{2} \mathrm{H}_{2}$ ) on grain surfaces with hydrogen (reduction reactions) and oxygen (or $\mathrm{OH}$; oxidation reactions) are known to produce more complex molecular species that can then be stored as ices in cometary nuclei. In the infrared, comparing measured abundances (among comets) of $\mathrm{CO}$ and $\mathrm{C}_{2} \mathrm{H}_{2}$ to species produced through their reduction on grain surfaces $\left(\mathrm{CH}_{3} \mathrm{OH}\right.$ and $\mathrm{C}_{2} \mathrm{H}_{6}$, 
Table A1

Estimates of water fraction released in the coma on UT 2011 October 13.

\begin{tabular}{|c|c|c|c|c|}
\hline & Excess/total & $\sigma($ excess/total $)$ & Mean KL1, KL2 & $\sigma$ Mean KL1, KL2 \\
\hline \multicolumn{5}{|c|}{ (1) Summing over residual and total profiles ${ }^{\mathrm{a}}$} \\
\hline KL1 & 0.248 & 0.0600 & 0.296 & 0.0296 \\
\hline KL2 & 0.311 & 0.0340 & & \\
\hline KL12 & 0.289 & 0.0404 & & \\
\hline \multicolumn{5}{|c|}{ (2) Based on Q-curve analysis ${ }^{\mathrm{b}}$} \\
\hline KL1 & 0.263 & 0.0528 & 0.284 & 0.0368 \\
\hline KL2 & 0.304 & 0.0514 & & \\
\hline
\end{tabular}

a Fraction of total $\mathrm{H}_{2} \mathrm{O}$ attributable to the excess emission at projected distance $1300-1500 \mathrm{~km}$ sunward of the nucleus, along with its $1 \sigma$ error, based on summing over its central $3000 \mathrm{~km}$, corresponding approximately to the range in projected distance -100 to $+2900 \mathrm{~km}$ in Fig. A1. Weighted mean from KL1 and KL2 is listed to the right. The entries for KL12 correspond to summing over the residual excess profile in Fig. A1c, representing the weighted mean of those from KL1 (Fig. A1a) and KL2 (Fig. A1b). The corresponding weighted mean fraction obtained by summing over the central $4000 \mathrm{~km}$ is $0.268 \pm 0.049$, consistent with the "Mean KL1, KL2" value (0.289) listed in the table.

b Fraction of total $\mathrm{H}_{2} \mathrm{O}$ from symmetrized $Q$-curves. Localized isotropic release is assumed, as would be expected from large and therefore slow-moving particles, although this could be realized even for a distribution of particle sizes (see Appendix A).

respectively) provides a potential means of testing the relative influence of oxidation.

However, compositional measurements provide only the net processing history of ices as opposed to their initial abundances on grain surfaces. Their interpretation is therefore subject to caveats, for example: (1) Oxidation of $\mathrm{CO}$ leads to $\mathrm{CO}_{2}$, which has recently been measured with surprisingly high abundance in a significant fraction of comets, frequently higher than the $\mathrm{CO}$ abundance (Ootsubo et al., 2012). Directly measuring $\mathrm{CO}_{2}$ requires observations from space and, including C/2009 P1 (Feaga et al., 2012), $\mathrm{CO}_{2}$ has been measured in only three comets for which the suite of primary volatile abundances have also been characterized using IR spectroscopy, the others being 9P/Tempel 1 (Mumma et al., 2005; Feaga et al., 2007) and 103P/Hartley 2 (Dello Russo et al., 2011; Mumma et al., 2011; Weaver et al., 2011, A'Hearn, 2011). (2) H-atom addition to $\mathrm{CO}$ produces $\mathrm{H}_{2} \mathrm{CO}$ in addition to $\mathrm{CH}_{3} \mathrm{OH}$. Native, monomeric formaldehyde $\left(\mathrm{H}_{2} \mathrm{CO}\right)$ has been measured in a number of comets, ${ }^{5}$ however the amount contained in polymers is typically unknown, and where measured - in 1P/Halley (Eberhardt, 1999, and references therein) and C/1995 01 Hale-Bopp (Wink et al., 1999) - its abundance dominates that of monomeric $\mathrm{H}_{2} \mathrm{CO}$ in the nucleus.

A complete assessment must investigate all viable formation pathways for oxidized carbon compounds, including gas-phase production of species like $\mathrm{CO}_{2}$ and $\mathrm{H}_{2} \mathrm{CO}$ (Walsh et al., 2012) and also addition reactions on the surfaces of (interstellar) grains (Oba et al., 2010; Watanabe et al., 2004). Here we discuss the potential usefulness and limitations of measured abundances in comets in the context of grain-surface reactions.

\subsection{Reduction on grains}

Hydrogen atom addition to $\mathrm{C}_{2} \mathrm{H}_{2}$ on the surfaces of interstellar grains as a means of producing $\mathrm{C}_{2} \mathrm{H}_{4}$ and then $\mathrm{C}_{2} \mathrm{H}_{6}$ was suggested by Tielens (1992), and was later borne out by the discovery of abundant ethane in comet C/1996 B2 (Hyakutake) (Mumma et al., 1996). Measurement of $\mathrm{C}_{2} \mathrm{H}_{6}$ in nearly all subsequent comets established this molecule as an important constituent in cometary

\footnotetext{
5 The combination of small (sub-arc-second) beam sizes of modern IR spectrometers such as NIRSPEC, together with the relatively small distance between A- and Bbeam positions (Section 2 ) favors measurement of species released directly from the nucleus (i.e., of "native" abundances as defined previously).
}

ices (e.g., see Mumma and Charnley, 2011; DiSanti and Mumma, 2008; Bockelée-Morvan et al., 2005, and references therein), and $\mathrm{H}$-atom addition as both common and significant in the evolution of pre-cometary ices.

Similarly, $\mathrm{H}$-atom addition to $\mathrm{CO}$ on grains produces the highlyreactive formyl radical ( $\mathrm{HCO}$ ), which readily converts to $\mathrm{H}_{2} \mathrm{CO}$ and then to $\mathrm{CH}_{3} \mathrm{OH}$. This was addressed theoretically (Charnley and Rodgers, 2009), and also was demonstrated observationally as a far more efficient means of accounting for methanol abundances in interstellar sources compared with gas-phase ion-neutral chemistry (Wirström et al., 2011; Bottinelli et al., 2010). Laboratory irradiation experiments (Watanabe et al., 2004; Hudson and Moore, 1999) showed such surface reactions to be viable, providing significant product yields at very low temperatures (10-20 K), but with virtually no production at (or above) $\sim 25 \mathrm{~K}$ (Watanabe et al., 2004). Irradiation of $\mathrm{H}_{2} \mathrm{O}$ and $\mathrm{CO}$ ice mixtures at $10 \mathrm{~K}$ using energetic electrons (Bennett et al., 2011) and at $16 \mathrm{~K}$ with $0.8-\mathrm{MeV}$ protons (Hudson and Moore, 1999) also produced formic acid $(\mathrm{HCOOH})$. The relative abundances of $\mathrm{CO}, \mathrm{H}_{2} \mathrm{CO}$ and $\mathrm{CH}_{3} \mathrm{OH}$ in comets can test their inter-relationship, and the laboratory yields provide a comparison in assessing natal conditions.

Among the sample of comets measured at IR wavelengths, C/ 2009 P1 exhibited the most pronounced difference between abundances of $\mathrm{CO}$ (enriched) and $\mathrm{C}_{2} \mathrm{H}_{2}$ (strongly depleted). Given the preceding discussion, this appears at odds with our results indicating approximately "normal" abundances of $\mathrm{C}_{2} \mathrm{H}_{6}$ and $\mathrm{CH}_{3} \mathrm{OH}$. One possible explanation is more efficient conversion of initially less abundant $\mathrm{C}_{2} \mathrm{H}_{2}$ relative to $\mathrm{CO}$ on its pre-cometary grains (see Fig. 4 of Hiraoka et al., 2000 for temperature-dependence).

\subsection{Oxidation on grains}

Perhaps a more likely explanation includes oxidation reactions on icy grain mantles. Surface reactions of $\mathrm{CO}$ with $\mathrm{OH}$ are efficient at producing $\mathrm{CO}_{2}$ (Oba et al., 2010; Garrod and Pauly, 2011). This is supported by the preponderance of $\mathrm{CO}_{2}$ ice toward interstellar sources observed with ISO (Ehrenfreund et al., 1997; Gibb et al., 2004), and the detection of $\mathrm{CO}_{2}$ in 17 of 18 comets surveyed by AKARI (Ootsubo et al., 2012) and in three comets measured by Deep Impact/DIXI (9P/Tempel 1; Feaga et al., 2007, 103P/Hartley 2; A'Hearn, 2011, and C/2009 P1; Feaga et al., 2012). It was recently postulated that a significant fraction of comets from both $\mathrm{KB}$ and $\mathrm{OC}$ reservoirs formed in overlapping regions between $\mathrm{CO}$ and $\mathrm{CO}_{2}$ snow lines (A'Hearn et al., 2012).

\subsection{Combined reduction and oxidation ("redox") on grains}

Hydrogen-atom addition to $\mathrm{C}_{2} \mathrm{H}_{2}$ produces the vinyl radical $\left(\mathrm{CH}_{2} \mathrm{CH}\right)$. Subjecting this to subsequent oxidation/reduction leads to three isomers of $\mathrm{C}_{2} \mathrm{H}_{4} \mathrm{O}$ : ethylene oxide $\left(\mathrm{c}-\mathrm{C}_{2} \mathrm{H}_{4} \mathrm{O}\right)$, vinyl alcohol $\left(\mathrm{CH}_{2} \mathrm{CHOH}\right)$, and acetaldehyde $\left(\mathrm{CH}_{3} \mathrm{CHO}\right)$ (Ward and Price, 2011). Hydrogenation of the latter two isomers provides a viable means of producing ethanol $\left(\mathrm{CH}_{3} \mathrm{CH}_{2} \mathrm{OH}\right)$ (see Charnley, 2004). These studies together with our findings for $\mathrm{C} / 2009 \mathrm{P} 1$ and perhaps other comets with high $\mathrm{CO} / \mathrm{C}_{2} \mathrm{H}_{2}$ (e.g., C/1999 T1 and C/1996 B2; see Table 4, Fig. 6 , and discussion below) suggest that in general both oxidation and reduction should be considered.

Our results for C/2009 P1 may represent a case in point. If its pre-cometary ices were subjected to processing that included significant oxidation reactions, this could help explain its high $\mathrm{CO} /$ $\mathrm{C}_{2} \mathrm{H}_{2}$ abundance ratio together with its "normal" $\mathrm{C}_{2} \mathrm{H}_{6}$ and $\mathrm{CH}_{3} \mathrm{OH}$. The depleted acetylene in $\mathrm{C} / 2009 \mathrm{P} 1$ could result from its conversion not only to ethane but also to the above $\mathrm{C}_{2} \mathrm{H}_{4} \mathrm{O}$ isomers and perhaps to $\mathrm{CH}_{3} \mathrm{CH}_{2} \mathrm{OH}$. Furthermore, its high $\mathrm{CO}_{2} / \mathrm{H}_{2} \mathrm{O}$ abundance ratio (Feaga et al., 2012) suggests its "initial" CO endowment (i.e., the amount of CO condensed onto its pre-cometary grains) 
may have been considerably larger than the value we observe (9.1\%).

\subsection{Comparison among comets}

Fig. 6 compares abundance ratios $\mathrm{CO} / \mathrm{C}_{2} \mathrm{H}_{2}$ versus $\mathrm{CH}_{3} \mathrm{OH} / \mathrm{C}_{2} \mathrm{H}_{6}$ in 16 comets identified by number in Table 4. Points well above the horizontal dotted line (median $\mathrm{CO} / \mathrm{H}_{2} \mathrm{O}$, "normal" $\mathrm{C}_{2} \mathrm{H}_{2} / \mathrm{H}_{2} \mathrm{O}$ ) and near or to the left of the vertical dotted line ("normal" $\mathrm{CH}_{3} \mathrm{OH} / \mathrm{H}_{2} \mathrm{O}$ and $\mathrm{C}_{2} \mathrm{H}_{6} / \mathrm{H}_{2} \mathrm{O}$ ) could indicate a relatively more important role for oxidation reactions, and correspondingly that the ices incorporated into such comets were subjected to processing in relatively oxygen-rich environments. Considering the $\mathrm{CH}_{3} \mathrm{CHO}$ observed in star forming regions (Charnley, 2004), measuring or stringently constraining its abundance in comets ${ }^{6}$ having high $\mathrm{CO} / \mathrm{C}_{2} \mathrm{H}_{2}$ yet modest $\mathrm{CH}_{3} \mathrm{OH} / \mathrm{C}_{2} \mathrm{H}_{6}$ can test this hypothesis. However, it is important to bear in mind that, considering the aforementioned caveats (Section 6.1), comets with lower $\mathrm{CO} / \mathrm{C}_{2} \mathrm{H}_{2}$ must also be considered, for example if a significant fraction of their "initial" (i.e., condensed interstellar) $\mathrm{CO}$ is incorporated into unaccounted-for polymers (e.g., formaldehyde polymers) and/or $\mathrm{CO}_{2}$.

\section{Summary}

On UT 2011 October 13 ( $R_{h}=1.836$ AU pre-perihelion) we measured nine primary volatiles $\left(\mathrm{H}_{2} \mathrm{O}, \mathrm{CO}, \mathrm{CH}_{4}, \mathrm{C}_{2} \mathrm{H}_{2}, \mathrm{C}_{2} \mathrm{H}_{6}, \mathrm{H}_{2} \mathrm{CO}\right.$, $\mathrm{CH}_{3} \mathrm{OH}, \mathrm{HCN}$, and $\mathrm{NH}_{3}$ ) in Comet $\mathrm{C} / 2009$ P1 (Garradd). On 2012 January $8\left(R_{h}=1.566 \mathrm{AU}\right.$ post-perihelion) we measured three of these $\left(\mathrm{H}_{2} \mathrm{O}, \mathrm{HCN}\right.$, and $\left.\mathrm{CH}_{4}\right)$ and obtained meaningful upper limits for three others $\left(\mathrm{H}_{2} \mathrm{CO}, \mathrm{NH}_{3}\right.$, and $\left.\mathrm{C}_{2} \mathrm{H}_{2}\right)$. Our measured abundance ratios relative to $\mathrm{H}_{2} \mathrm{O}$ did not change pre- and post-perihelion, suggesting compositional homogeneity among species measured on both dates, to the depths among active regions sampled. However, despite its smaller heliocentric distance, $Q\left(\mathrm{H}_{2} \mathrm{O}\right)$ was lower by approximately $23 \%$ on January 8 compared with October 13 , qualitatively similar to pre-/post-perihelion differences in water production revealed by SOHO/SWAN observations of C/2009 P1.

Comparison of spatial profiles revealed differences in outgassing among volatiles in C/2009 P1. Pre-perihelion profiles for $\mathrm{CH}_{4}, \mathrm{CO}, \mathrm{C}_{2} \mathrm{H}_{6}$ and $\mathrm{HCN}$ showed fairly similar spatial distributions, suggesting these four species originated from one or more active regions composed predominantly of a-polar ice. Most pronounced was the sunward-hemisphere-facing excess in $\mathrm{H}_{2} \mathrm{O}$ emission on October 13 having peak intensity at projected distance 1300$1500 \mathrm{~km}$ from the nucleus. This was not seen in other profiles, consistent with release from relatively pure, polar (water-rich) ice particles liberated from the nucleus, perhaps in a directed flow. We estimate that $25-30 \%$ of the total $\mathrm{H}_{2} \mathrm{O}$ encompassed in our slit was released in the coma. Along with $\mathrm{C} / 2007 \mathrm{~W} 1$ (Boattini) and 103P/Hartley 2, C/2009 P1 is the third recent comet to show evidence for (at least) two distinct phases of ice within the nucleus.

The lack of excess $\mathrm{H}_{2} \mathrm{O}$ emission together with its lower water production on January 8 suggest loss of the source of icy grains. This plus similar decreases in production of $\mathrm{HCN}$ and $\mathrm{CH}_{4}$ may result from depletion of ice in, or covering of, one or more active regions on the nucleus, or perhaps more likely from pre-/postperihelion differences in orientation relative to the incident solar radiation.

Our results for comet C/2009 P1 add a unique signature to our growing taxonomy of primary volatile abundances in comets. Its enriched $\mathrm{CO}$ and severely depleted $\mathrm{C}_{2} \mathrm{H}_{2}$, together with "normal" $\mathrm{C}_{2} \mathrm{H}_{6}$ and $\mathrm{CH}_{3} \mathrm{OH}$, could indicate that its ices were processed in a

\footnotetext{
${ }^{6}$ An abundance ratio $\mathrm{CH}_{3} \mathrm{CHO} / \mathrm{H}_{2} \mathrm{O}=0.02 \%$ was reported for $\mathrm{C} / 199501$ (HaleBopp) (Crovisier et al., 2004).
}

relatively oxygen-rich environment prior to their incorporation into the nucleus.

\section{Acknowledgments}

We gratefully acknowledge support through the NASA Astrobiology Institute under Cooperative Agreements (RTOP 344-53-51 to GSFC, and NNA09DA77A to U. Hawai'i), the NASA Planetary Astronomy Program (RTOPs 09-PAST09-0034, 344-32-07), the NASA Planetary Atmospheres Program (RTOPs 09-PATM-0080, 12PATM12-0049), the National Science Foundation Astronomy and Astrophysics Grants Program (AST-1211362, AST-0807939), and the NASA Postdoctoral Program. We thank two anonymous reviewers for comments that improved the paper. M.A.D. thanks S. Charnley for fruitful discussions regarding surface chemistry of interstellar ices, and R. Novak for participating in the January 8 observations. The data presented herein were obtained at the W.M. Keck Observatory, operated as a scientific partnership among CalTech, UCLA, and NASA, and made possible by the generous financial support of the W.M. Keck Foundation. The authors recognize the very significant cultural role and reverence that the summit of Mauna Kea has always had within the indigenous Hawaiian community. We are most fortunate for the opportunity to conduct observations from this mountain.

\section{Appendix A. Distinguishing pre-perihelion sources of $\mathrm{H}_{2} \mathrm{O}$ in C/2009 P1}

\section{A.1. Quantitative estimate of coma source contribution}

Fig. A1 illustrates the approach we used for quantitatively estimating the fraction of water released in the coma of $\mathrm{C} / 2009 \mathrm{P} 1$. We express the $\mathrm{H}_{2} \mathrm{O}$ profiles in terms of column density $\mathrm{N}_{\text {beam }}\left(\mathrm{H}_{2} \mathrm{O}\right.$ molecules $\mathrm{m}^{-2}$ ) averaged within a beam centered approximately $350 \mathrm{~km}$ sunward of the nucleus - corresponding to the approximate peak position of Gaussian fits to the water profiles - and having area $\left(A_{\text {beam }}\right)$ corresponding to $2400 \times 580 \mathrm{~km}$ at the comet. This is related to the "nucleus-centered" production rate $\left(Q_{\mathrm{nc}}\right)$ as (see DiSanti et al., 2009 for formalism):

$N_{\text {beam }}=\frac{Q_{\mathrm{nc}}}{A_{\text {beam }}} \tau_{1 \mathrm{AU}} f(x) R_{h}^{2}$

where $R_{h}$ is expressed in AU.

We isolated the fraction of water released in the coma as follows. We combined the profiles for $\mathrm{HCN}$ (Fig. 4b) and $\mathrm{C}_{2} \mathrm{H}_{6}$ (Fig. 4f), after scaling each to a common level when averaged over $\pm 1200 \mathrm{~km}$ from the nucleus. Both $\mathrm{C}_{2} \mathrm{H}_{6}$ and $\mathrm{HCN}$ profiles had very similar growth factors $(\sim 1.5)$ and showed relatively large degrees of sunward/anti-sunward symmetry. We take this combined profile to closely approximate purely native release of primary volatiles, and refer to it as our "representative native profile." We separately scale this to the total $\mathrm{H}_{2} \mathrm{O}$ intensity over the range 0 to $-4000 \mathrm{~km}$ in the KL1 and KL2 settings; this range is indicated by the horizontal bar in each panel of Fig. A1.

The residual profile obtained by subtracting this scaled representative native profile provides a measure of the excess $\mathrm{H}_{2} \mathrm{O}$ released in the coma and contained within our slit. We took two independent approaches to quantifying this fraction (excess water/total water): (1) We summed the residual $\mathrm{H}_{2} \mathrm{O}$ profile intensities in KL1 and KL2 from approximately -100 to $+2900 \mathrm{~km}$, and compared these to the corresponding sums for the total $\mathrm{H}_{2} \mathrm{O}$ profile. (2) We applied our standard " $Q$-curve" analysis to the residual $\mathrm{H}_{2} \mathrm{O}$ profiles (for details of this formalism, see discussions in Dello Russo et al., 1998; DiSanti et al., 2001; Bonev et al., 2005), and 
compared the terminal $Q$ to that obtained from the total $\mathrm{H}_{2} \mathrm{O}$ profile (the latter corresponding to $Q_{\text {tot }}$ for $\mathrm{H}_{2} \mathrm{O}$ in the $\mathrm{KL} 1$ and $\mathrm{KL} 2$ settings on October 13; Table 2). The resulting fractions are summarized in Table A1. These indicate agreement between approaches (1) and (2), with both contributing $25-30 \%$ of the total water production we observe in C/2009 P1 on October 13 being released in the coma and peaking in the sunward-facing hemisphere at projected distance $1300-1500 \mathrm{~km}$ from the nucleus. Interestingly, a study of HDO in C/2009 P1 with HIFI on the Herschel space craft provided the most consistent match to observed line profiles if a comparable fraction of water (30\%) was adopted for release from icy grains in the coma (Bockelée-Morvan et al., 2012). However, given the much larger Herschel aperture, comparisons with our results may not be meaningful.

Because we must allow for possible additional release of $\mathrm{H}_{2} \mathrm{O}$ in the coma but not encompassed in the slit, this fraction of "excess" $\mathrm{H}_{2} \mathrm{O}$ to total $\mathrm{H}_{2} \mathrm{O}$ could represent a lower bound. If larger, such additional release may explain the difference in water production reported here versus those from optical observations (Section 4.2) and pre-perihelion SOHO H-Ly $\alpha$ measurements (Section 4.3).

\section{A.2. Possible interpretation of excess $\mathrm{H}_{2} \mathrm{O}$ release}

The most straightforward explanation for the observed excess water in $\mathrm{C} / 2009 \mathrm{P} 1$ is release from $\mathrm{H}_{2} \mathrm{O}$-rich icy particles. These could arise from one or more active regions on the nucleus that contain an over-abundance of polar (specifically, water-rich) ice compared with the source(s) of activity giving rise to the ambient coma gas. This could be part of a directed outflow that releases predominantly the water-rich ice component giving rise to the observed excess $\mathrm{H}_{2} \mathrm{O}$.

The excess $\mathrm{H}_{2} \mathrm{O}$ peaks at a relatively localized projected distance from the nucleus $(\sim 1300-1500 \mathrm{~km})$. If polar-ice-dominated particles are the explanation, the distance at which they release water is determined by the product of their outflow speeds and their sublimation lifetimes. We consider a range of particle sizes, from submicron to the largest particles that can be lifted off the nucleus by the sublimation process. This maximum particle size can be estimated by balancing gravitational and gas drag forces at the surface of the nucleus (see Delsemme and Miller, 1971):

$\alpha_{\max }=\frac{9}{16 \pi} \frac{m v_{\text {gas }} Z}{\mathrm{G} R_{c} \rho_{c} \rho_{g}}$

In Eq. (A2), $m$ is the mean molecular mass of the coma gas (taken to be $\sim 20 \mathrm{amu}$ ), $Z$ is the gas sublimation rate (molecules $\mathrm{s}^{-1} \mathrm{~cm}^{-2}$ ), $R_{c}$ is the radius of the nucleus $(\mathrm{km})$, and $\rho_{c}$ and $\rho_{g}$ are densities $\left(\mathrm{gm} \mathrm{cm}^{-3}\right)$ of the bulk nucleus and the particle, respectively. Assuming reasonable values $\left(R_{C}=2 \mathrm{~km}\right.$, a native gas production rate of $8 \times 10^{28}$ molecules s $^{-1}$, and $\rho_{c}=\rho_{g}=1$ ) leads to $a_{\max } \sim 5 \mathrm{~cm}$. Particles this large would remain very close to the surface of the nucleus and move very slowly. Indeed, the clumps of water-ice observed during the EPOXI flyby of 103P/Hartley 2 had extremely low velocities $\left(<2 \mathrm{~m} \mathrm{~s}^{-1}\right)$, with only one of 50 tracked in space craft images found beyond $15 \mathrm{~km}$ from the nucleus (A'Hearn, 2011).

The smallest particles will maintain an outflow speed closer to (but still below) $v_{\text {gas }}$, assumed to be $0.59 \mathrm{~km} \mathrm{~s}^{-1}$ at $R_{h}=1.83 \mathrm{AU}$ (Section 3.2), thereby requiring a lifetime of approximately 2200-2600 s for release in the region of peak excess water emission. (We note the relatively small phase angle of $31.6^{\circ}$ on UT 2011 October 13 means that if release occurs along the actual comet-Sun direction, this distance and therefore the required particle lifetimes are approximately doubled.)

This lifetime is consistent with grains dominated by water ice, as predicted by modeled sublimation of grains composed of admixtures of water ice and rocky material (i.e., "dirty" grains; Beer et al.,
2006). Using a parameter $X_{1}$ (=mass water-ice $_{\text {mass }}$ grain), Beer et al. predict the lifetime of pure water ice grains $\left(X_{1}=1\right)$ to be about $10^{5} \mathrm{~s}$ at $1.8 \mathrm{AU}$, even for small grains of size $a=0.1 \mu \mathrm{m}$. However, the predicted lifetime drops precipitously when even a small fraction of refractory material is present (e.g., to $10^{3} \mathrm{~s}$ for $X_{1}=0.9$ ). Large grains (but still much smaller than $a_{\text {max }}$; e.g., $a=1 \mathrm{~mm}$ ) having $X_{1}=0.9$ are predicted to survive for $\sim 10^{5} \mathrm{~s}$, and these could release $\mathrm{H}_{2} \mathrm{O}$ in the coma on the observed scale provided their outflow speed is, as one would expect, much lower (20-30 $\left.\mathrm{m} \mathrm{s}^{-1}\right)$. If associated with a nucleus rotation period of $10.4 \mathrm{~h}$ (see Section 3.3), the "distance doubling" seen in the KL2 water profile (Fig. 4a) implies a similar mean (projected) particle speed of $\sim 40 \mathrm{~m} \mathrm{~s}^{-1}$. In this manner, our observations of "excess" $\mathrm{H}_{2} \mathrm{O}$ in C/2009 P1 can be explained by relatively localized release from relatively pure-water icy grains $\left(0.9<X_{1}<1.0\right)$ spanning a wide range of sizes.

\section{References}

A'Hearn, M.F., 2011. Comets as building blocks. Ann. Rev. Astron. Astrophys. 49, 281-299.

A'Hearn, M.F., Feaga, L.M., Keller, H.U., et al., 2012. Cometary volatiles and the origin of comets. Astrophys. J. 758 (1), 1-8 (article ID 29).

Beer, E.H., Podolak, M., Prialnik, D., 2006. The contribution of icy grains to the activity of comets. I. Grain lifetime and distribution. Icarus 180 (2), 473-486.

Bennett, C.J., Hama, T., Kim, S.Y., Kawasaki, M., Kaiser, R.I., 2011. Laboratory studies on the formation of formic acid $(\mathrm{HCOOH})$ in interstellar and cometary ices. Astrophys. J. 727 (27), 1-15.

Biver, N., Bockelée-Morvan, D., Crovisier, J., et al., 1999a. Spectroscopic monitoring of Comet C/1996 B2 (Hyakutake) with the JCMT and IRAM radio telescopes. Astron. J. 118, 1850-1872.

Biver, N., Bockelée-Morvan, D., Colom, P., et al., 1999b. Long-term evolution of the outgassing of Comet Hale-Bopp from radio observations. Earth, Moon, Planets 78, 5-11.

Biver, N., Bockelée-Morvan, D. Crovisier, J., Colom, P., Henry, F., et al., 2002 Chemical composition diversity among 24 comets observed at radio wavelengths. Earth, Moon, Planets 90, 323-333.

Biver, N., Bockelée-Morvan, D., Crovisier, J., Lis, D.C., Moreno, R., et al., 2006. Radio wavelength molecular observations of comets C/1999 T1 (McNaught-Hartley), C/2001 A2 (LINEAR), C/2000 WM1 (LINEAR), and 153P/Ikeya-Zhang. Astron. Astrophys. 449, 1255-1270.

Biver, N., Bockelée-Morvan, D., Lis, D.C., et al., 2012. Molecular survey of Comet C 2009 P1 (Garradd) at mm to submm wavelengths. Asteroids, Comets, Meteors 2012, LPI Contribution No. 1667. ID 6330.

Bockelée-Morvan, D., Crovisier, J., Mumma, M.J., Weaver, H.A., 2005. The composition of cometary volatiles. In: Festou, M.C., Keller, H.U., Weaver, H.A. (Eds.), Comets II. University of Arizona Press, Tucson, pp. 391-423.

Bockelée-Morvan, D., Henry, F., Biver, N., et al., 2009. Interferometric imaging of carbon monoxide in Comet C/1995 01 (Hale-Bopp): Evidence of a strong rotating jet. Astron. Astrophys. 505, 825-843.

Bockelée-Morvan, D., Biver, N., Swinyard, B., et al., 2012. Herschel measurements of the $\mathrm{D} / \mathrm{H}$ and ${ }^{16} \mathrm{O} /{ }^{18} \mathrm{O}$ ratios in water in the Oort-cloud comet $\mathrm{C} / 2009 \mathrm{P} 1$ (Garradd). Astron. Astrophys. 544, L15-L20.

Bodewits, D., Farnham, T., A'Hearn, M.F., 2012. Comet C/2009 P1 (Garradd). CBET 3090, 1.

Böhnhardt, H., Mumma, M.J., Villanueva, G.L., DiSanti, M.A., Bonev, B.P., Lippi, M., Kaufel, H.U., 2008. The unusual volatile composition of the Halley-type comet 8P/Tuttle: Addressing the existence of an inner Oort cloud. Astrophys. J. 683, L71-L74.

Bonev, B.P., 2005. Towards a Chemical Taxonomy of Comets: Infrared Spectroscopic Methods for Quantitative Measurements of Cometary Water (with an Independent Chapter on Mars Polar Science). PhD Thesis, The University of Toledo.

Bonev, B.P. et al., 2006. A comprehensive study of infrared $\mathrm{OH}$ prompt emission in two comets. I. Observations and effective g-factors. Astrophys. J. 653, 774-787.

Bonev, B.P., Mumma, M.J., Radeva, Y.L., DiSanti, M.A., Gibb, E.L., Villanueva, G.L., 2008. The peculiar volatile composition of Comet 8P/Tuttle: A contact binary of chemically distinct cometesimals? Astrophys. J. 680, L61-L64.

Bonev, B.P., Mumma, M.J., Gibb, E.L., DiSanti, 2009. Comet C/2004 Q2 (Machholz): Parent volatiles, a search for deuterated methane, and constraint on the $\mathrm{CH}_{4}$ spin temperature. Astrophys. J. 699, 1563-1572.

Bottinelli, S., Adwin Boogert, A.C., Bouwman, J., 2010. The c2d Spitzer spectroscopic survey of ices around low-mas Young Stellar Objects. IV. $\mathrm{NH}_{3}$ and $\mathrm{CH}_{3} \mathrm{OH}$. Astrophys. J. 718, 1100-1117.

Brasser, R., Duncan, M.J., Levison, H.F., Schwamb, M.E., Brown, M.E., 2012. Reassessing the formation of the inner Oort cloud in an embedded star cluster. Icarus 217, 1-19.

Charnley, S.B., 2004. Acetaldehyde in star-forming regions. Adv. Space Res. 33, 23 30.

Charnley, S.B., Rodgers, S.D., 2009. Theoretical models of complex molecule formation on dust. In: Meech, K.J., Keane, J.V., Mumma, M.J., Siefert, J.L., 
Werthimer, D.J. (Eds.), Bioastronomy 2007: Molecules, Microbes, and Extraterrestrial Life. ASP Conference Series, vol. 420.

Clough, S.A. et al., 2005. Atmospheric radiative transfer modeling: A summary of the AER codes. J. Quant. Spectrosc. Radiat. Trans. 91, 233. http://dx.doi.org/10.1016/ j.jqsit.2004.05.058.

Combi, M.R., Makinen, J.T.T., Bertaux, J., Quemerais, E., Ferron, S., 2012. Water production rate of Comet 2009 P1 (Garradd) throughout the 2011-2012 apparition: Evidence for an icy grain halo. Icarus 225, 740-748.

Crovisier, J., Bockelée-Morvan, D., Colom, P., Biver, N., et al., 2004. The composition of ices in Comet C/1995 O1 (H-B) from radio spectroscopy. Astron. Astrophys. 418, 1141-1157.

Dello Russo, N., DiSanti, M.A., Mumma, M.J., Magee-Sauer, K., Rettig, T.W., 1998 Carbonyl sulfide in Comets C/1996 B2 (Hyakutake) and C/1995 01 (Hale-Bopp): Evidence for an extended source in Hale-Bopp. Icarus 135 (2), 377-388.

Dello Russo, N., Mumma, M.J., DiSanti, M.A., Magee-Sauer, K., 2002a. Production of ethane and water in comet C/1996 B2 Hyakutake. J. Geophys. Res. - Planets 107 (E11), 1-11.

Dello Russo, N., DiSanti, M.A., Magee-Sauer, K., Gibb, E., Mumma, M.J., 2002b. Production of $\mathrm{C}_{2} \mathrm{H}_{6}$ and $\mathrm{H}_{2} \mathrm{O}$ in Comet $2002 \mathrm{C} 1$ Ikeya-Zhang on UT 2002 Apri 13.7-13.9. In: Proc. Asteroids, Comets, Meteors 2002. ESA-SP 500, pp. 689-692.

Dello Russo, N., Vervack Jr., R.J., Weaver, H.A., 2007. Compositional homogeneity in the fragmented Comet 73P/Schwassmann-Wachmann 3. Nature (Lett.) 448 $172-175$.

Dello Russo, N., Vervack Jr., R.J., Lisse, C.M., et al., 2011. The volatile composition and activity of Comet 103P/Hartley 2 during the EPOXI closest approach. Astrophys. J. 734 (L8), 1-6.

Delsemme, A.H., Miller, D.C., 1971. Physico-chemical phenomena in comets - III: The continuum of Comet Burnham (1960 II). Planet. Space Sci. 19, 1229-1257.

DiSanti, M.A., Mumma, M.J., 2008. Reservoirs for comets: Compositional differences based on infrared observations. Space Sci. Rev. 138 (1), 127-146.

DiSanti, M.A., Mumma, M.J., Dello Russo, N., Magee-Sauer, K., 2001. Carbon monoxide production and excitation in Comet C/1995 01 (Hale-Bopp): Isolation of native and distributed CO sources. Icarus 153, 361-390.

DiSanti, M.A., Dello Russo, N., Magee-Sauer, K., Gibb, E.L., Mumma, M.J., 2002. CO, $\mathrm{H}_{2} \mathrm{CO}$, and $\mathrm{CH}_{3} \mathrm{OH}$ in Comet $2002 \mathrm{C} 1$ (Ikeya-Zhang). In: Proc. Asteroids, Comets, Meteors 2002. ESA-SP 500, pp. 571-574

DiSanti, M.A., Mumma, M.J., Dello Russo, N., Magee-Sauer, K., Griep, D.M., 2003. Evidence for a dominant native source of carbon monoxide in Comet C/1996 B2 (Hyakutake). J. Geophys. Res. - Planets 108 (E6), 1-19. http://dx.doi.org 10.1029/2002JE001961.

DiSanti, M.A. et al., 2006. Detection of formaldehyde emission in Comet C/2002 T7 (LINEAR) at infrared wavelengths: Line-by-line validation of modeled fluorescent intensities. Astrophys. J. 650, 470-483.

DiSanti, M.A., Anderson, W.M., Villanueva, G.L., et al., 2007. Depleted carbon monoxide in fragment $\mathrm{C}$ of the Jupiter Family Comet 73P/SchwassmannWachmann 3. Astrophys. J. 661, L101-L104.

DiSanti, M.A., Villanueva, G.L., Milam, S.N., et al., 2009. A multi-wavelength study of parent volatile abundances in Comet C/2006 M4 (SWAN). Icarus 203, 589-598.

DiSanti, M.A., Bonev, B.P., Villanueva, G.L., Mumma, M.J., 2013. Highly depleted ethane and mildly depleted methanol in Comet 21P/Giacobini-Zinner: Application of a new empirical $v_{2}$ band model for $\mathrm{CH}_{3} \mathrm{OH}$ near $50 \mathrm{~K}$ Astrophys. J. 763, 1-19.

Eberhardt, P., 1999. Comet Halley's gas composition and extended sources: Results from the neutral mass spectrometer on Giotto. Space Sci. Rev. 90, 45-52.

Eberhardt, P., Meier, R., Krankowsky, D., Hodges, R.R., 1994. Methanol and hydrogen sulfide in Comet P/Halley. Astron. Astrophys. 288, 315-329.

Ehrenfreund, P., d'Hendecourt, L., Dartois, E., Jourdain de Muizon, M., Breitfellner, M., et al., 1997. ISO observations of interstellar ices and implications for comets. Icarus 130, 1-15.

Feaga, L.M., A'Hearn, M.F., Sunshine, J.M., Groussin, O., Farnham, T.L., 2007. Asymmetries in the distribution of $\mathrm{H}_{2} \mathrm{O}$ and $\mathrm{CO}_{2}$ in the inner coma of Comet 9P/Tempel 1 as observed by Deep Impact. Icarus 191, 134-145.

Feaga, L.M., A'Hearn, M., Farnham, T., Gersch, A., Bodewits, D., Klaasen, K., 2012. A study of C/2009 P1 Garradd's dominant volatiles as observed by the Deep Impact HRI-IR spectrometer. American Astronomical Society, DPS meeting \#44, \#313.08.

Garrod, R.T., Pauly, T., 2011. On the formation of $\mathrm{CO}_{2}$ and other interstellar ices. Astrophys. J. 735 (15), 1-18.

Gibb, E.L., Mumma, M.J., Dello Russo, N., DiSanti, M.A., Magee-Sauer, K., 2003. Methane in Oort cloud comets. Icarus 165, 391-406.

Gibb, E.L., Whittet, D.C.B., Boogert, A.C.A., Tielens, A.G.G.M., 2004. Interstellar ices: The Infrared Space Observatory legacy. Astrophys. J. 151 (Suppl.), 35-73.

Gibb, E.L., Bonev, B.P., Villanueva, G.L., DiSanti, M.A., et al., 2012. Chemical composition of Comet C/2007 N3 (Lulin): Another "atypical" comet. Astrophys. J. 750, 102-115.

Gomes, R., Levison, H.F., Tsiganis, K., Morbidelli, A., 2005. Origin of the cataclysmic Late Heavy Bombardment period of the terrestrial planets. Nature 435, 466-469.

Hiraoka, K., Takayama, T., Euchi, A., Handa, H., Sato, T., 2000. Study of the reactions of $\mathrm{H}$ and $\mathrm{D}$ atoms with solid $\mathrm{C}_{2} \mathrm{H}_{2}, \mathrm{C}_{2} \mathrm{H}_{4}$, and $\mathrm{C}_{2} \mathrm{H}_{6}$ at cryogenic temperatures. Astrophys. J. 532, 1029-1037.

Hudson, R.L., Moore, M.H., 1999. Laboratory studies of the formation of methanol and other organic molecules by water + carbon monoxide radiolysis: Relevance to comets, icy satellites and interstellar ices. Icarus 140, 451-461.

Kawakita, H., Mumma, M.J., 2011. Fluorescence excitation models of ammonia and amidogen radical $\left(\mathrm{NH}_{2}\right)$ in comets: Application to Comet C/2004 Q2 (Machholz). Astrophys. J. 727 (91), 1-11.
Levison, H.F., Duncan, M.J., Brasser, R., Kaufmann, D.E., 2010. Capture of the Sun's Oort cloud from stars in its birth cluster. Science 329 (5), 187-190.

Lippi, M., Villanueva, G.L., DiSanti, M.A., et al., 2013. A new model for the nu1 band of $\mathrm{HCN}$ in cometary comae, with application to three comets. Astron. Astrophys. 551 (A51), 1-9.

Magee-Sauer, K., Mumma, M.J., DiSanti, M.A., Dello Russo, N., 1999. Infrared spectroscopy of the $v_{3}$ band of hydrogen cyanide in Comet C/1995 01 HaleBopp. Icarus 142, 498-508.

Magee-Sauer, K., Mumma, M., DiSanti, M.A., Dello Russo, N., 2002a. Hydrogen cyanide in Comet C/1996 B2 Hyakutake. J. Geophys. Res. - Planets 107 (E11), 1 10.

Magee-Sauer, K., Dello Russo, N., DiSanti, M.A., 2002b. Production of $\mathrm{HCN}$ and $\mathrm{C}_{2} \mathrm{H}_{2}$ in Comet C/2002 C1 Ikeya-Zhang on UT 2002 April 13.8. In: Proc. Asteroids, Comets, Meteors 2002. ESA-SP 500, pp. 548-552.

Magee-Sauer, K., Mumma, M.J., Bonev, B.P., Radeva, Y.L., DiSanti, M.A., Villanueva, G.L., et al., 2008a. Asteroids, Comets, Meteors Conf., LPI Contribution No. 1405 Paper ID 8054.

Magee-Sauer, K., Mumma, M.J., DiSanti, M.A., Dello Russo, N., Gibb, E.L., Bonev, B.P., Villanueva, G.L., et al., 2008b. The organic composition of Comet C/2001 A2 (LINEAR). I. Evidence for an unusual organic chemistry. Icarus 194, 347-356.

McKay, A., Chanover, N., DiSanti, M., Morgenthaler, J.P., Cochran, A., et al., 2012. Infrared and optical spectroscopy of Comet C/2009 P1 Garradd: CO abundance and implications for the atomic oxygen yield from $\mathrm{CO}$ photodissociation American Astronomical Society, DPS meeting \#44, \#506.09. <http:/ adsabs.harvard.edu/abs/2012DPS. ...4450609M>.

McLean, I.S., Becklin, E.E., Bendiksen, O., et al., 1998. Design and development of NIRSPEC: A near-infrared echelle spectrograph for the Keck II telescope. Proc. SPIE 3354, 566-578.

McLean, I.S., Graham, J.R., Becklin, E.E., et al., 2000. Performance and results with the NIRSPEC echelle spectrograph on the Keck II telescope. Proc. SPIE 4008, 1048 1055.

Morbidelli, A., Levison, H.F., Gomes, R., 2008. The dynamical structure of the Kuiper belt and its primordial origin. In: The Solar System Beyond Neptune, pp. 275292.

Mumma, M.J., Charnley, S.B., 2011. The chemical composition of comets - Emerging taxonomies and natal heritage. Annu. Rev. Astron. Astrophys. 49, 471-524.

Mumma, M.J., Weissman, P.R., Stern, S.A., 1993. Comets and the early Solar System: Reading the Rosetta Stone. In: Levy, E.H., Lunine, J.I. (Eds.), Protostars and Planets III, pp. 1177-1252.

Mumma, M.J. et al., 1996. Detection of abundant ethane and methane, along with carbon monoxide and water, in Comet C/1996 B2 Hyakutake: Evidence for interstellar origin. Science 272, 1310-1314.

Mumma, M.J., McLean, I.S., DiSanti, M.A., Larkin, J.E., Dello Russo, N., 2001a. A survey of organic volatile species in Comet C/1999 H1 (Lee) using NIRSPEC at the Keck Observatory. Astrophys. J. 546, 1183-1193.

Mumma, M.J., Russo, Dello.N., DiSanti, M.A., Magee-Sauer, K., Novak, R.E., Brittain, S., 2001b. Organic composition of C/1999 S4 (LINEAR): A comet formed near Jupiter? Science 292 (5), 1334-1339.

Mumma, M.J. et al., 2001c. Comet C/1999 T1 (McNaught-Hartley). IAU Circ. 7578.

Mumma, M.J. et al., 2005. Direct measurement of parent volatiles in Comet 9P/ Tempel 1: A comparison of volatile composition before and after impact. Science 310, 270-274.

Mumma, M.J., Bonev, B.P., Villanueva, G.L., Paganini, L., DiSanti, M.A., Gibb, E.L., et al., 2011. Temporal and spatial aspects of gas release during the 2010 apparition of Comet 103P/Hartley 2. Astrophys. J. 734 (L7), 1-6.

Oba, Y., Watanabe, N., Kouchi, A., et al., 2010. Experimental study of $\mathrm{CO}_{2}$ formation by surface reactions of non-energetic $\mathrm{OH}$ radicals with $\mathrm{CO}$ molecules. Astrophys. J. 712, L174-L178.

Ootsubo, T., Kawakita, H., Hamada, S., Kobayashi, H., et al., 2012. AKARI near-infrared spectroscopic survey for $\mathrm{CO}_{2}$ in 18 comets. Astrophys. J. 752 (15), $1-12$

Paganini, L. et al., 2012. The chemical composition of CO-rich Comet C/2009 P1 (Garradd) at $R_{\mathrm{h}}=2.4$ and 2.0 AU before perihelion. Astrophys. J. 748 (L13), 1-7.

Radeva, Y.L., Mumma, M.J., Bonev, B.P., DiSanti, M.A., Villanueva, G.L., et al., 2010. The organic composition of Comet C/2000 WM1 (LINEAR) revealed through infrared spectroscopy. Icarus 206, 764-777.

Reuter, D.C., Mumma, M.J., Nadler, S., 1989. Infrared fluorescence efficiencies for the nu1 and nu5 bands of formaldehyde in the solar radiation field. Astrophys. J. 341, 1045-1058.

Stern, S.A., 2003. The evolution of comets in the Oort cloud and Kuiper belt. Nature 424, 639-642.

Tielens, A.G.G.M., 1992. Grain surface chemistry. In: Chemistry and Spectroscopy of Interstellar Molecules. University of Tokyo Press, p. 237.

Villanueva, G.L., Bonev, B.P., Mumma, M.J., et al., 2006. The volatile composition of the split ecliptic Comet 73P/Schwassmann-Wachmann 3: A comparison of fragments C and B. Astrophys. J. 650, L87-L90.

Villanueva, G.L., Mumma, M.J., DiSanti, M.A., Bonev, B.P., Gibb, E.L., Magee-Sauer, K., et al., 2011a. The molecular composition of Comet C/2007 W1 (Boattini): Evidence of a peculiar outgassing and a rich chemistry. Icarus 216, 227-240.

Villanueva, G.L., Mumma, M.J., Magee-Sauer, K., 2011b. Ethane in planetary and cometary atmospheres: Transmittance and fluorescence models of the $v_{7}$ band at $3.3 \mu \mathrm{m}$. J. Geophys. Res. 116 (E08012), 1-23.

Villanueva, G.L., Mumma, M.J., Bonev, B.P., Novak, R.E., Barber, R.J., DiSanti, M.A. 2012a. Water in planetary and cometary atmospheres: $\mathrm{H}_{2} \mathrm{O} / \mathrm{HDO}$ transmittances and fluorescence models. J. Quant. Spectrosc. Radiat. Trans. $113,202-220$. 
Villanueva, G.L., DiSanti, M.A., Mumma, M.J., Xu, L.-H., 2012b. A quantum band model of the $v_{3}$ fundamental of methanol $\left(\mathrm{CH}_{3} \mathrm{OH}\right)$ and its application to fluorescence spectra of comets. Astrophys. J. 747 (37), 1-11.

Villanueva, G.L., Mumma, M.J., DiSanti, M.A., Bonev, B.P., Paganini, L., Blake, G.A., 2012c. A multi-instrument study of Comet C/2009 P1 (Garradd) at 2.1 AU (preperihelion) from the Sun. Icarus 220, 291-295 (Notes).

Villanueva, G.L., Magee-Sauer, K., Mumma, M.J., 2013. Modeling of nitrogen compounds in cometary atmospheres: Fluorescence models of ammonia $\left(\mathrm{NH}_{3}\right)$, hydrogen cyanide $(\mathrm{HCN})$, hydrogen isocyanide (HNC) and cyanoacetylene $\left(\mathrm{HC}_{3} \mathrm{~N}\right)$. J. Quant. Spectrosc. Radiat. Trans. 129, 158-168.

Walsh, K.J., Morbidelli, A., 2011. The effect of an early planetesimal-driven migration of the giant planets on terrestrial planet migration. Astron. Astrophys. 526 (A126), 1-8.

Walsh, C., Nomura, H., Millar, T.J., Aikawa, Y., 2012. Chemical processes in protoplanetary disks. II. On the importance of photochemistry and X-ray ionization. Astrophys. J. 747 (114), 1-19.
Ward, M.D., Price, S.D., 2011. Thermal reactions of oxygen atoms with alkenes at low temperatures on interstellar dust. Astrophys. J. 741 (121), 1-9.

Watanabe, N., Nagaoka, A., Shiraki, T., Kouchi, A., 2004. Hydrogenation of CO on pure solid $\mathrm{CO}$ and $\mathrm{CO}-\mathrm{H}_{2} \mathrm{O}$ mixed ice. Astrophys. J. 616, 638-642.

Weaver, H.A., Feldman, P.D., A'Hearn, M.F., Dello Russo, N., Stern, S.A., 2011. The carbon monoxide abundance in Comet 103P/Hartley 2 during the EPOXI flyby. Astrophys. J. 734 (L5), 1-5.

Wink, J., Bockelée-Morvan, D., Despois, D., et al., 1999. Evidences for extended sources and temporal modulations in molecular observations of C/1995 01 (Hale-Bopp) at the IRAM interferometer. Earth, Moon, Planets 78, 63.

Wirström, E.S., Geppert, W.D., Hjalmarson, A., et al., 2011. Observational tests of interstellar methanol formation. Astron. Astrophys. 533 (A24), 1-11.

Xie, X., Mumma, M.J., 1996. Monte Carlo simulation of cometary atmospheres: Application to Comet $\mathrm{P} /$ Halley at the time of the GIOTTO space craft encounter. II. Axisymmetric model. Astrophys. J. 464, 457-475. 